\title{
Development and characterization
} of acidic-pH-tolerant mutants of Zymomonas mobilis through adaptation and next-generation sequencing-based genome resequencing and RNA-Seq

Qing Yang ${ }^{1 \dagger}$, Yongfu Yang ${ }^{1 \dagger}$, Ying Tang ${ }^{1}$, Xia Wang ${ }^{1}$, Yunhao Chen ${ }^{1}$, Wei Shen ${ }^{1}$, Yangyang Zhan ${ }^{1}$, Junjie Gao ${ }^{1}$, Bo $\mathrm{Wu}^{2}$, Mingxiong $\mathrm{He}^{2}$, Shouwen Chen ${ }^{1}$ and Shihui Yang ${ }^{1 *}$ (])

\begin{abstract}
Background: Acid pretreatment is a common strategy used to break down the hemicellulose component of the lignocellulosic biomass to release pentoses, and a subsequent enzymatic hydrolysis step is usually applied to release hexoses from the cellulose. The hydrolysate after pretreatment and enzymatic hydrolysis containing both hexoses and pentoses can then be used as substrates for biochemical production. However, the acid-pretreated liquor can also be directly used as the substrate for microbial fermentation, which has an acidic $\mathrm{pH}$ and contains inhibitory compounds generated during pretreatment. Although the natural ethanologenic bacterium Zymomonas mobilis can grow in a broad range of $\mathrm{pH} 3.5 \sim 7.5$, cell growth and ethanol fermentation are still affected under acidic-pH conditions below $\mathrm{pH}$ 4.0.

Results: In this study, adaptive laboratory evolution (ALE) strategy was applied to adapt Z. mobilis under acidic-pH conditions. Two mutant strains named 3.6M and 3.5M with enhanced acidic pH tolerance were selected and confirmed, of which 3.5M grew better than ZM4 but worse than 3.6M in acidic-pH conditions that is served as a reference strain between 3.6M and ZM4 to help unravel the acidic-pH tolerance mechanism. Mutant strains 3.5M and 3.6M exhibited $50 \sim 130 \%$ enhancement on growth rate, $4 \sim 9 \mathrm{~h}$ reduction on fermentation time to consume glucose, and $20 \sim 63 \%$ improvement on ethanol productivity than wild-type ZM4 at pH 3.8. Next-generation sequencing (NGS)-based whole-genome resequencing (WGR) and RNA-Seq technologies were applied to unravel the acidic-pH tolerance mechanism of mutant strains. WGR result indicated that compared to wild-type ZM4, 3.5M and 3.6M have seven and five single nucleotide polymorphisms (SNPs), respectively, among which four are shared in common. Additionally, RNA-Seq result showed that the upregulation of genes involved in glycolysis and the downregulation of flagellar and mobility related genes would help generate and redistribute cellular energy to resist acidic pH while keeping normal biological processes in Z. mobilis. Moreover, genes involved in RND efflux pump, ATP-binding cassette
\end{abstract}

\footnotetext{
*Correspondence: Shihui.Yang@hubuedu.cn

${ }^{+}$Qing Yang and Yongfu Yang contributed equally to this work

${ }^{1}$ State Key Laboratory of Biocatalysis and Enzyme Engineering,

Environmental Microbial Technology Center of Hubei Province and School of Life Sciences, Hubei University, Wuhan 430062, China

Full list of author information is available at the end of the article
}

c) The Author(s) 2020. This article is licensed under a Creative Commons Attribution 4.0 International License, which permits use, sharing, adaptation, distribution and reproduction in any medium or format, as long as you give appropriate credit to the original author(s) and the source, provide a link to the Creative Commons licence, and indicate if changes were made. The images or other third party material in this article are included in the article's Creative Commons licence, unless indicated otherwise in a credit line to the material. If material is not included in the article's Creative Commons licence and your intended use is not permitted by statutory regulation or exceeds the permitted use, you will need to obtain permission directly from the copyright holder. To view a copy of this licence, visit http://creativeco mmons.org/licenses/by/4.0/. The Creative Commons Public Domain Dedication waiver (http://creativecommons.org/publicdomain/ zero/1.0/) applies to the data made available in this article, unless otherwise stated in a credit line to the data. 
(ABC) transporter, proton consumption, and alkaline metabolite production were significantly upregulated in mutants under the acidic-pH condition compared with ZM4, which could help maintain the $\mathrm{pH}$ homeostasis in mutant strains for acidic-pH resistance. Furthermore, our results demonstrated that in mutant $3.6 \mathrm{M}$, genes encoding $\mathrm{F}_{1} \mathrm{~F}_{0}$ ATPase to pump excess protons out of cells were upregulated under $\mathrm{pH} 3.8$ compared to $\mathrm{pH}$ 6.2. This difference might help mutant 3.6M manage acidic conditions better than ZM4 and 3.5M. A few gene targets were then selected for genetics study to explore their role in acidic $\mathrm{pH}$ tolerance, and our results demonstrated that the expression of two operons in the shuttle plasmids, ZMO0956-ZMO0958 encoding cytochrome bc1 complex and ZMO1428-ZMO1432 encoding RND efflux pump, could help Z. mobilis tolerate acidic-pH conditions.

Conclusion: An acidic-pH-tolerant mutant 3.6M obtained through this study can be used for commercial bioethanol production under acidic fermentation conditions. In addition, the molecular mechanism of acidic pH tolerance of Z. mobilis was further proposed, which can facilitate future research on rational design of synthetic microorganisms with enhanced tolerance against acidic-pH conditions. Moreover, the strategy developed in this study combining approaches of ALE, genome resequencing, RNA-Seq, and classical genetics study for mutant evolution and characterization can be applied in other industrial microorganisms.

Keywords: Zymomonas mobilis, Adaptive laboratory evolution (ALE), Acidic pH tolerance, Next-generation sequencing (NGS), RNA-Seq, Whole-genome resequencing (WGR)

\section{Background}

With the global climate change caused by burning fossil fuels and the growing demand for energy [1, 2], sustainable bioenergy has drawn great attentions [3]. Currently, bioethanol, an environmental-friendly renewable liquid biofuel, has been intensively studied as one of the most promising alternatives to fossil fuels $[4,5]$. However, bioethanol has been produced primarily from food crops with high content of sugar and starch thus far, which would compete with the food supply and could potentially lead to a global food crisis.

Lignocellulosic materials, derived mainly from agriculture wastes or forestry residues, are the most abundant, low-cost, and promising feedstocks for bioethanol production [6, 7]. However, these biomass resources are naturally recalcitrant, which require deconstruction processes such as size reduction and pretreatment to breakdown the rigid biomass structure to release fermentable sugars for subsequent microbial fermentation $[8,9]$. Among different pretreatment methods, acid pretreatment is a prevailing strategy used to break down the hemicellulose component of the lignocellulosic biomass to release pentoses, such as xylose and arabinose, and is usually followed by a subsequent enzymatic hydrolysis step to release hexoses from the cellulose, which can be used as substrates for biochemical production. The acidpretreated liquor can also be directly used as the substrate for microbial fermentation, which has an acidic $\mathrm{pH}$ and contains inhibitory compounds generated during pretreatment and consequently impedes cell growth resulting in reduced ethanol titer and productivity $[10$, $11]$.

To minimize the detrimental effect of acidic $\mathrm{pH}$ on microbes, acid-pretreated liquor must be neutralized by high-cost processes such as extra chemical addition before microbial fermentation, especially in large industrial scales [12], whereas a natural acidic-pH condition of acid-pretreated liquor provides an opportunity to effectively prevent the potential bacterial contamination and makes the open (non-sterilized) fermentation applicable $[13,14]$. It is reported that ethanol production under the non-sterilized condition can save 30 40\% energy consumption and make the process simpler [15]. Hence, it will be ideal to develop more acidic-pH-tolerant strains for ethanol production, which has been developed in species, such as Escherichia coli $[16,17]$ and yeast [12, 18, 19].

Zymomonas mobilis is a facultative anaerobic and natural ethanologenic bacterium with desirable industrial biocatalyst characteristics, such as a highly specific rate of sugar uptake, high ethanol yield, no oxygen requirement for cell growth and ethanol fermentation, and a relatively low biomass production during fermentation [20, 21]. In addition, $Z$. mobilis has a generally regarded as safe (GRAS) status [22, 23]. Up until now, many different stress-tolerant strains of $Z$. mobilis have been constructed with enhanced tolerance to acetate [24, 25], furfural [26, 27], and hydrolysate [28, 29]. However, acidic-pH conditions are still a challenge for Z. mobilis using lignocellulosic feedstock hydrolyzed by acid as the substrate. For example, Z. mobilis NS-7 is an acid-tolerant strain developed by nitrosoguanidine (NTG) mutation and acid medium selection, which can ferment at an acidic $\mathrm{pH}$ of 4.5 under non-sterilized condition without being contaminated [15]. Z. mobilis GZNS1 is another mutant strain evolved by culturing at $\mathrm{pH} 4.0$ condition that could produce ethanol from acidic kitchen garbage [14]. An increased acid tolerance was also observed in $Z$. 
mobilis recombinant strain carrying $\mathrm{Pbp}$ (proton-buffering peptide, $\mathrm{Pbp}$ ) from E. coli [30].

In addition, some genomic variants relevant to acid tolerance in $Z$. mobilis have been identified. For example, the acetate-tolerant phenotype in AcR mutant may be due to the over-expression of $Z M O 0119$ encoding $\mathrm{Na}^{+} /$ $\mathrm{H}^{+}$antiporter resulting from a $1.5-\mathrm{kb}$ deletion in AcR mutant $[24,25]$. And single nucleotide variants (SNVs) in genes ZMO0056 and ZMO0589, which encode a glutamine-fructose-6-phosphate aminotransferase and a DNA repair protein RadA, respectively, have been characterized to likely contribute to acid tolerance in mutant stains developed by a multi-round atmospheric and room temperature plasma (mARTP) mutagenesis [31]. Nevertheless, it is still a challenge to develop strains tolerant to acidic $\mathrm{pH}$ due to the lack of a comprehensive understanding on functional genomics and molecular regulation responsible for the acid tolerance in $Z$. mobilis.

Adaptive laboratory evolution (ALE) is a powerful tool for strain development with desired stable phenotypes without requiring knowledge of any underlying genetic mechanism [32-34]. It has been successfully applied in model organisms, such as E. coli $[35,36]$ and Saccharomyces cerevisiae [37, 38]. After obtaining mutant strains, next-generation sequencing (NGS) based strategies such as whole-genome resequencing (WGR) and RNA sequencing (RNA-Seq) are usually applied to reveal genetic and global gene expression changes [39]. Currently, ALE strategy has been employed for strain improvement in $Z$. mobilis, including inhibitor tolerance $[27,28]$ and substrate utilization [40-42]. In this study, ALE was performed under acidic-pH conditions to select $Z$. mobilis mutant strains with enhanced acidic $\mathrm{pH}$ tolerance. WGR and RNA-Seq technologies were then applied to investigate the genotypic changes associated with acidic $\mathrm{pH}$ tolerance revealing the molecular mechanism responsible for the improved acidic $\mathrm{pH}$ tolerance in mutant strains.

\section{Results and discussion}

Development of acidic-pH-tolerant mutants of $Z$. mobilis through adaptive laboratory evolution (ALE)

Zymomonas mobilis was reported to be able to grow within a broad range of pH $3.5 \sim 7.5$ [21]. In this study, the growth of $Z$. mobilis in $\mathrm{pH}$ range below $\mathrm{pH} 4.0$ was further investigated. The results showed that ZM4 can grow below pH 4.0 (Fig. 1), which is consistent with previous reports $[21,43]$. However, when the $\mathrm{pH}$ value decreased from 4.0 to 3.5, a longer lag phase was observed accompanied by a lower biomass production (Fig. 1). Cells almost could not grow at pH 3.5 (Fig. 1), which might be ascribed to the damage of cell membrane structure and protein configuration at acidic $\mathrm{pH}$ [44]. Therefore, the

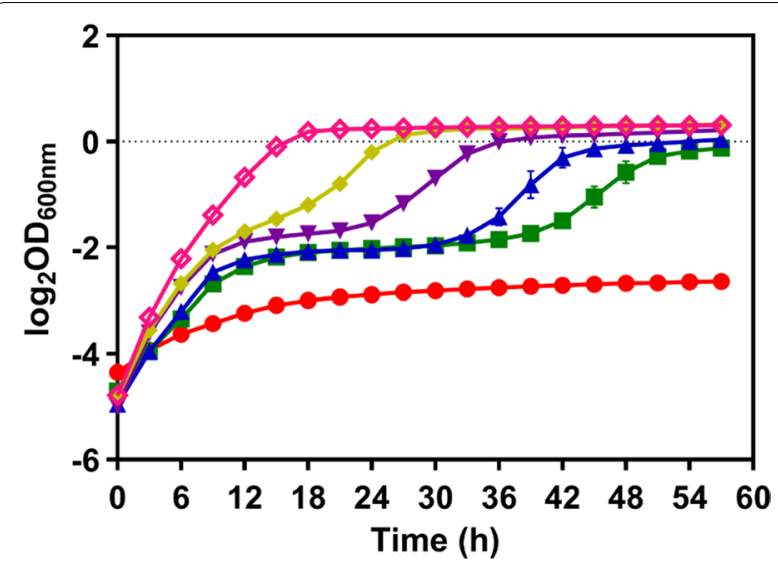

Fig. 1 Cell growth of wild-type Z. mobilis ZM4 under different $\mathrm{pH}$ conditions. ZM4 was cultured in RMG5 using Bioscreen C instrument at a pH range within $\mathrm{pH}$ 3.5-4.0. pH 3.5 (red color circle), pH 3.6 (green color square), pH 3.7 (blue color upward triangle), pH 3.8 (purple color downward triangle), pH 3.9 (yellow color diamond), and pH 4.0 (pink color diamond). At least two independent experiments were performed with similar results. Values are the mean of one representative experiment with three technical replicates. Error bars represent standard deviations

development of acidic-pH-tolerant strains could directly benefit commercial bioethanol production under acidic fermentation conditions.

Subsequently, adaptive laboratory evolution (ALE) was carried out with two parallel experiments in RMG2 medium, which was firstly adapted at $\mathrm{pH} 4.0$ with $30 \mathrm{cul}-$ tivation cycles and then transferred to $\mathrm{pH} 3.5$ and $\mathrm{pH}$ 3.6 for acidic-pH resistance evolution (Fig. 2a). Finally, after 55 and 75 cultivation cycles at $\mathrm{pH} 3.5$ and $\mathrm{pH}$ 3.6, respectively, four evolved mutants, named as $3.5 \mathrm{M}$ $1,3.5 \mathrm{M}-2,3.6 \mathrm{M}-1$, and $3.6 \mathrm{M}-2$, with enhanced acidic $\mathrm{pH}$ tolerance were obtained. The stability of these four adapted mutants was then analyzed at $\mathrm{pH} 3.6$ with three colonies of each as replicates. The results showed that the growth of replicates from $3.5 \mathrm{M}-1$ and $3.6 \mathrm{M}-1$ was more uniformed than those of $3.5 \mathrm{M}-2$ and $3.6 \mathrm{M}-2$ (Fig. 2b). The growth of these four mutants was then further compared with wild-type ZM4 under different $\mathrm{pH}$ conditions of $\mathrm{pH} 3.5, \mathrm{pH} 3.6, \mathrm{pH} 4.0$, and $\mathrm{pH} 6.0$ (Fig. 3).

Under the condition of $\mathrm{pH} 3.5$ (Fig. 3a), all four mutants had higher growth rates and final $\mathrm{OD}_{600}$ values than ZM4, among which the mutant 3.6M-1 exhibited the highest $\mathrm{OD}_{600}$ value of cell growth, followed by $3.6 \mathrm{M}-2,3.5 \mathrm{M}-2$ and $3.5 \mathrm{M}-1$ successively. Under $\mathrm{pH} 3.6$ condition, the mutants also had higher growth rates and shorter times reaching stationary phase than ZM4 (Fig. 3b). The mutants had no obvious disadvantages compared to ZM4 except that 3.5M-1 had a lower final $\mathrm{OD}_{600}$ value at both $\mathrm{pH} 4.0$ and $\mathrm{pH} 6.0$ (Fig. 3c, d). These 


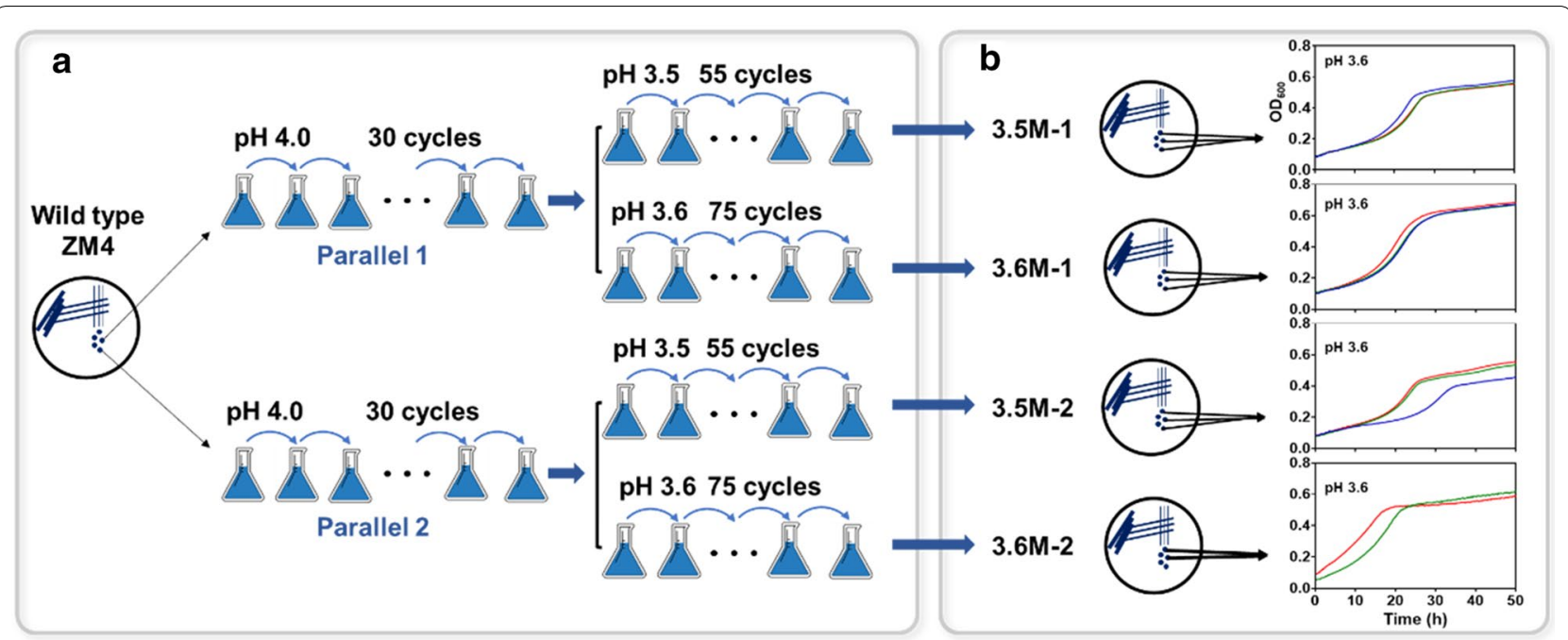

Fig. 2 The workflow to obtain acidic-pH resistant mutants of Z. mobilis ZM4 through adaptive laboratory evolution (ALE) in RMG2 media (a), and the verification and selection of mutants with stable acidic-pH resistance under $\mathrm{pH} 3.6$ culture condition (b)
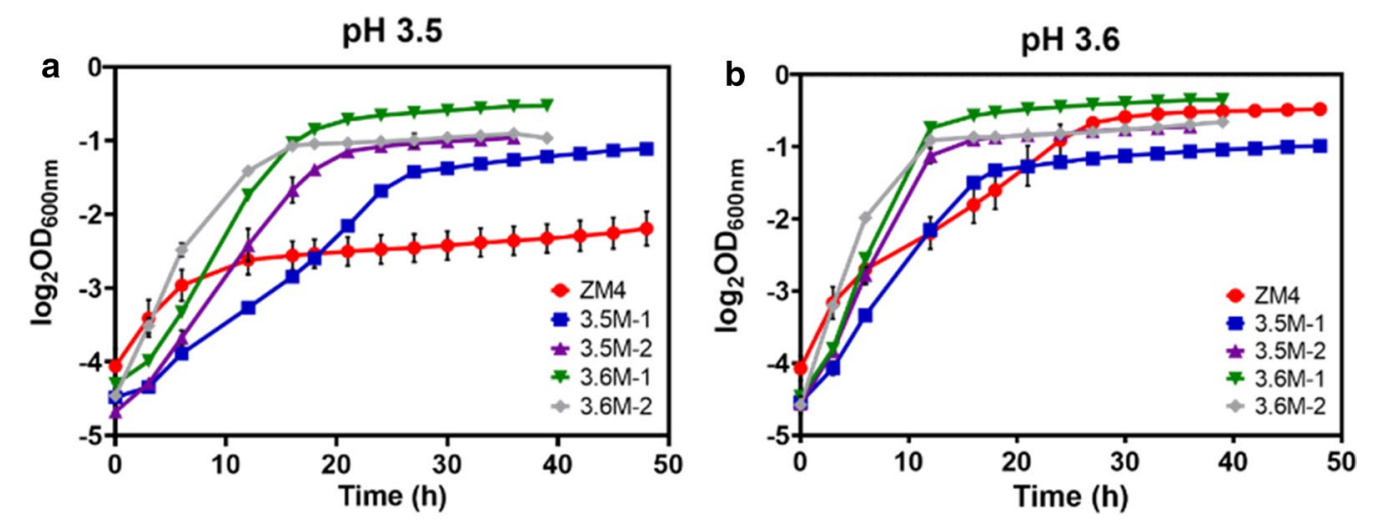

pH 4.0
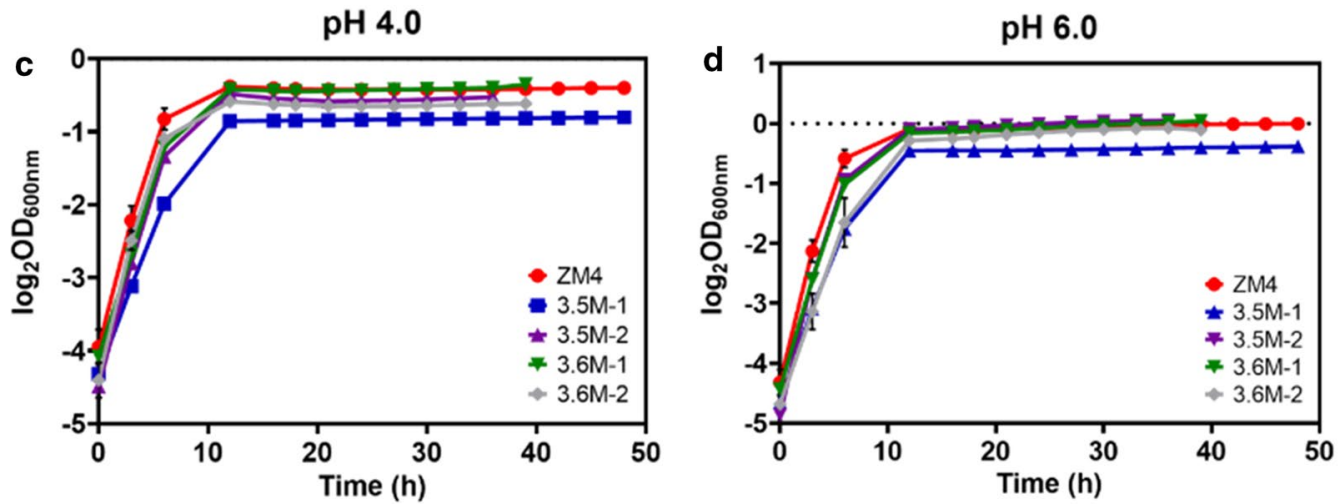

Fig. 3 Cell growth of four acidic-pH-tolerant mutants of 3.5M-1, 3.5M-2, 3.6M-1, and 3.6M-2 and wild-type Z. mobilis ZM4 under different pH conditions of pH 3.5 (a), pH 3.6 (b), pH 4.0 (c), and pH 6.0 (d) in RMG2. OD values at 600 nm were monitored using Bioscreen C instrument. At least two independent experiments were performed with similar results. Values are the mean of one representative experiment with three technical replicates. Error bars represent standard deviations 
results suggested that although all mutants had enhanced tolerance at acidic-pH conditions, their performance was different. To understand the molecular mechanism of acidic-pH resistance, two mutants $3.5 \mathrm{M}-1$ and $3.6 \mathrm{M}-1$ with growth differences from ZM4 were selected and renamed as $3.5 \mathrm{M}$ and $3.6 \mathrm{M}$ correspondingly for further studies. $3.6 \mathrm{M}-1$ is the best acidic-pH-tolerant mutant based on its highest final $\mathrm{OD}_{600}$ values among all mutants and wild-type ZM4 in acidic-pH conditions. Another acidic-pH-tolerant mutant $3.5 \mathrm{M}-1$ was selected because it grew better than $\mathrm{ZM} 4$ at $\mathrm{pH} 3.5$ while having the largest difference from 3.6M-1 in various conditions (Fig. 3).

\section{Evaluation of cell growth, glucose consumption,} and ethanol production of mutant strains $3.5 \mathrm{M}$ and $3.6 \mathrm{M}$ at acidic and neutral $\mathrm{pH}$ conditions

Since the acidic-pH conditions affect cell growth, glucose consumption, and ethanol production, two mutant strains $3.5 \mathrm{M}$ and $3.6 \mathrm{M}$ were investigated at acidic and neutral $\mathrm{pH}$ conditions of $\mathrm{pH} 3.8$ and $\mathrm{pH}$ 6.2, respectively. Both mutants $3.5 \mathrm{M}$ and $3.6 \mathrm{M}$ exhibited better cell growth and faster ethanol production than wildtype ZM4 at acidic pH 3.8 (Fig. 4a, b). The growth rates of $3.5 \mathrm{M}$ and $3.6 \mathrm{M}$ were $0.23 \mathrm{~h}^{-1}$ and $0.35 \mathrm{~h}^{-1}$, respectively, while that of ZM4 was only $0.14 \mathrm{~h}^{-1}$ (Table 1 ). Consistent with the fast cell growth and glucose consumption, the fermentation time were reduced significantly from $22 \mathrm{~h}$ for $\mathrm{ZM} 4$ to $18 \mathrm{~h}$ and $13 \mathrm{~h}$ for $3.5 \mathrm{M}$ and $3.6 \mathrm{M}$, respectively, leading to the increase of ethanol productivity by $21.21 \%$ and $64.65 \%$ correspondingly (Table 1; Fig. 4a, b).

Under the neutral $\mathrm{pH}$ condition of $\mathrm{pH}$ 6.2, cell growth, glucose consumption, and ethanol production of 3.6M were similar to those of ZM4, but were better than those of $3.5 \mathrm{M}$ (Table 1; Fig. 4c, d). These results suggested that $3.5 \mathrm{M}$ and $3.6 \mathrm{M}$ possessed relatively fast glucose consumption and ethanol production at the acidic- $\mathrm{pH}$ condition, and $3.6 \mathrm{M}$ maintained similar capacities as ZM4 at the neutral pH condition. Thus, $3.6 \mathrm{M}$ can be used to replace ZM4 as the biocatalyst for bioethanol production fermenting well in both acidic and neutral pH conditions (Table 1; Fig. 4c, d).

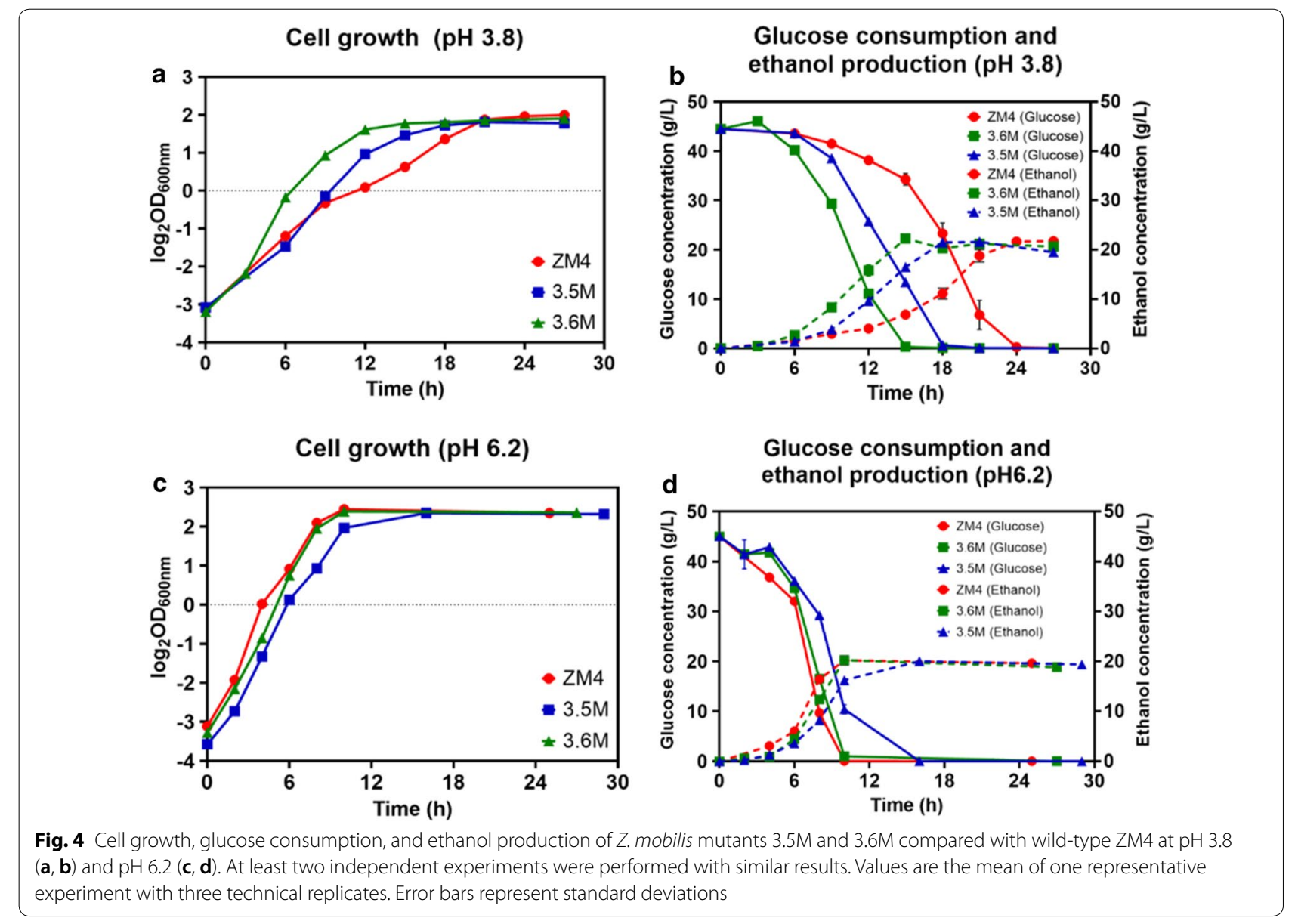


Table 1 Fermentation performance of time to consume all glucose (Time), growth rate, as well as ethanol titer, yield, and productivity of the wild-type $Z$. mobilis ZM4 and mutant strains 3.5M and 3.6M in RMG5 at pH 3.8 and pH 6.2

\begin{tabular}{|c|c|c|c|c|c|c|}
\hline $\begin{array}{l}\text { Condition } \\
\text { and Strain }\end{array}$ & Glucose used (g/L) & Time (h) & Growth rate $\left(\mathrm{h}^{-1}\right)$ & Titer (g/L) & Yield (\%) & Productivity $(\mathrm{g} / \mathrm{L} / \mathrm{h})$ \\
\hline \multicolumn{7}{|l|}{ pH 3.8} \\
\hline ZM4 & $44.95 \pm 0.12$ & 22 & $0.14 \pm 0.01$ & $21.74 \pm 0.43$ & $94.55 \pm 1.89$ & $0.99 \pm 0.02$ \\
\hline $3.5 \mathrm{M}$ & $44.91 \pm 0.01$ & 18 & $0.23 \pm 0.01$ & $21.62 \pm 0.14$ & $94.13 \pm 0.64$ & $1.20 \pm 0.01$ \\
\hline $3.6 \mathrm{M}$ & $44.98 \pm 0.00$ & 13 & $0.35 \pm 0.01$ & $21.22 \pm 0.28$ & $92.24 \pm 1.22$ & $1.63 \pm 0.02$ \\
\hline \multicolumn{7}{|l|}{ pH 6.2} \\
\hline ZM4 & $44.91 \pm 0.11$ & 10 & $0.49 \pm 0.007$ & $20.21 \pm 1.33$ & $87.99 \pm 5.88$ & $2.02 \pm 0.13$ \\
\hline $3.5 \mathrm{M}$ & $44.97 \pm 0.00$ & 12 & $0.39 \pm 0.005$ & $20.05 \pm 0.82$ & $87.19 \pm 3.56$ & $1.67 \pm 0.07$ \\
\hline $3.6 \mathrm{M}$ & $44.95 \pm 0.00$ & 10 & $0.49 \pm 0.01$ & $20.24 \pm 0.36$ & $90.00 \pm 1.20$ & $2.02 \pm 0.04$ \\
\hline
\end{tabular}

At least two independent experiments were performed with similar results. Values are the means and standard deviations of one representative experiment with three technical replicates

The underlying mechanism of acidic $\mathrm{pH}$ tolerance through NGS-based genome resequencing and RNA-Seq To illustrate the underlying genetic basis responsible for the enhanced acidic $\mathrm{pH}$ tolerance, samples of mutant and wild-type strains cultured at acidic $\mathrm{pH} 3.8$ and neutral pH 6.2 were collected for WGR to determine the genetic changes in $3.5 \mathrm{M}$ and $3.6 \mathrm{M}$ using the genome of parental strain ZM4 (ATCC 31821) as the Ref. [45]. RNA-Seq was also employed to explore the global transcriptional differences among these strains at acidic and neutral $\mathrm{pH}$ conditions.

The WGR results identified several SNPs in the mutants, including seven SNPs in 3.5M and five SNPs in $3.6 \mathrm{M}$, which are listed in Table 2. Among these mutations, four common SNPs were found in both mutants located at the coding sequence (CDS) region of four genes: ZMO0421 (A67T), ZMO0712 (G539D), ZMO1432 (P480L), and ZMO1733 (T7K), respectively (Fig. 5a). These common mutations may contribute to the enhanced acidic $\mathrm{pH}$ tolerance of mutant strains, while other unique mutations that are not shared by these strains may contribute to the unique phenotypic differences of these strains.

Additionally, the differentially expressed genes (DEGs) were identified through analysis of variance (ANOVA) using strains and different $\mathrm{pH}$ conditions as variables. A total of 781 genes were identified by comparing any two conditions with $P$ value $<0.05$ (Additional file 1: Table S1). There were 271, 362, and 498 DEGs comparing acidic $\mathrm{pH}$ 3.8 with neutral $\mathrm{pH} 6.2$ conditions of $3.5 \mathrm{M}, 3.6 \mathrm{M}$ and wild-type ZM4, respectively (Additional file 2: Fig. S1A). 246, 199 and 144 DEGs were also identified comparing $3.5 \mathrm{M}$ with $\mathrm{ZM} 4,3.6 \mathrm{M}$ with $\mathrm{ZM} 4$, and $3.5 \mathrm{M}$ with $3.6 \mathrm{M}$ at acidic $\mathrm{pH} 3.8$ conditions, respectively (Additional file 2: Fig. S1B). The DEGs from comparison of the same strain under different $\mathrm{pH}$ conditions or different strains under acidic $\mathrm{pH} 3.8$ conditions were then further analyzed.

\section{Association of genes with common changes in mutants with enhanced acidic $\mathrm{pH}$ tolerance}

A common mutation was found in gene ZMO0421, encoding histidinol-phosphate aminotransferase HisC2, which catalyzes the seventh step in the histidine

Table 2 Single-nucleotide polymorphisms (SNPs) in mutant strains 3.5M and 3.6M compared to wild-type ZM4

\begin{tabular}{|c|c|c|c|c|c|c|}
\hline Locus & SNP & AA change & $3.5 \mathrm{M}$ & $3.6 \mathrm{M}$ & Gene & Product \\
\hline 424761 & $\mathrm{C} / \mathrm{T}$ & A67T & 99.76 & 98.86 & ZMO0421 (hisC2) & Histidinol-phosphate aminotransferase \\
\hline 711194 & $\mathrm{G} / \mathrm{A}$ & G539D & 99.24 & 99.73 & ZM00712 (ppk) & Polyphosphate kinase \\
\hline 1449594 & $\mathrm{G} / \mathrm{A}$ & P480L & 100 & 99.72 & ZMO1432 & Efflux pump membrane component \\
\hline 1779278 & $\mathrm{C} / \mathrm{A}$ & T7K & 100 & 99.71 & ZMO1733 (oxyR) & Transcriptional regulator $\mathrm{OxyR}$ \\
\hline 1306151 & $\mathrm{C} / \mathrm{T}$ & W485* & 99.5 & - & ZMO1291 & Peptidase $\mathrm{S} 10$ serine carboxypeptidase \\
\hline 1701191 & $\mathrm{G} / \mathrm{A}$ & L77F & 99.08 & - & ZMO1651 (ptsP) & Signal transduction protein \\
\hline 173653 & $\mathrm{~T} / \mathrm{C}$ & & 100 & - & Intergenic region & Between ZMO0183 and ZMO0184 \\
\hline 1451222 & $A / G$ & & - & 100 & Intergenic region & Between ZMO1432 and ZMO1433 \\
\hline
\end{tabular}

The numbers in the columns of 3.5M and 3.6M represent the frequency (\%) of the SNP identified in all genome resequencing reads, and "- "indicates the absence of SNP. AA means amino acid. * indicates stop codon 


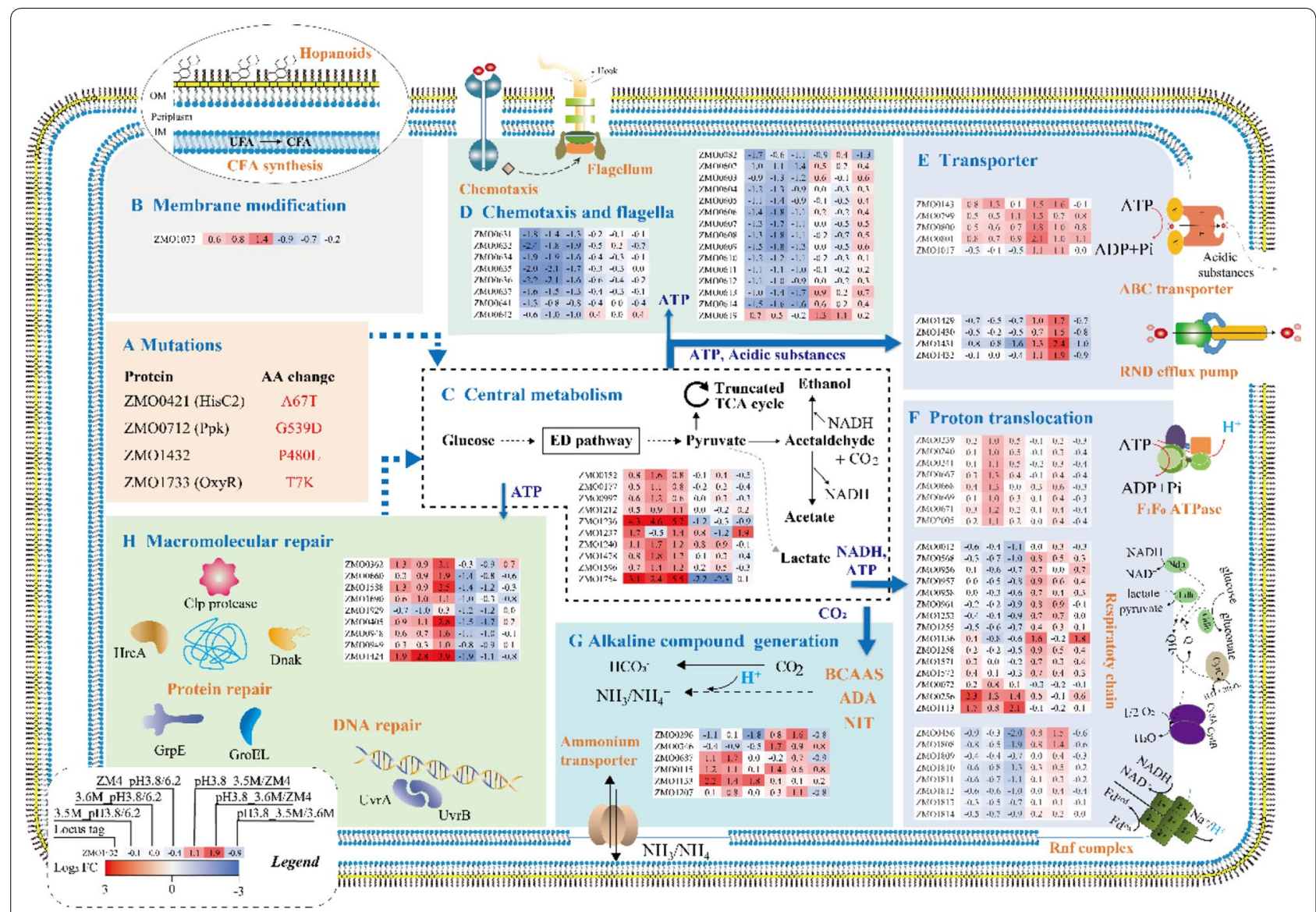

Fig. 5 Potential molecular mechanism of acidic-pH-tolerant mutant strains of Z. mobilis. Common mutations identified in two mutants (a); potential membrane modification (b); upregulation of the central metabolism producing enough ATP and reducing power (c); downregulation of flagella and chemotaxis reducing energy consumption (d); export of acidic substances by transporters (e); translocation of excess proton out of cell by $F_{1} F_{0}$ ATPase and electronic transport chain related complex (f); alkaline compound generation $(\mathbf{g})$; downregulation of macromolecular repair system (h). The numbers after the gene locus in shadow represent the $\log _{2}$-based fold changes. Red indicates upregulated, blue indicates downregulated. BCAAs: branched-chain amino acids, ADA: adenosine deaminase, NIT: nitrilase

biosynthesis pathway. Previous studies in Z. mobilis showed that HisC2 has broad substrate specificity and participates in transamination reactions for tyrosine and aromatic amino acid (phenylalanine) biosynthesis, which is essential in all studied organisms [46]. The A67T mutation in ZMO0421 was located in the amino transfer domain (PF00155, 32-357 aa) catalyzing the transamination reaction, which could likely affect enzymatic activity although detailed experiment is needed in the future.

Another common mutation was found in ppk gene (ZMO0712), which encodes polyphosphate kinase that transfers the $\gamma$-Pi of ATP to form a long chain polyphosphate (polyP) reversibly [47]. Several biological functions have been identified for cellular polyP including buffering capacities for $\mathrm{pH}$ homeostasis, DNA damage repair, cell cycle, motility, and biofilm formation [48-50]. Studies in other bacteria showed that polyP was rapidly accumulated by PPK under environmental stresses including acidic conditions [51-53]. Our transcriptomic data indicated that the expression of $p p k$ in wild-type ZM4 and mutant strains was upregulated at $\mathrm{pH} 3.8$ compared with $\mathrm{pH} 6.2$ (Additional file 3: Table S2), which is consistent with the conclusion reported above. Considering that the G539D mutation in PPK was located in the C2 domain (PF13090, 503-687), which is highly conserved in the PPK family and essential for the enzymatic activity [53], the mutation in this enzyme may help improve the activity of PPK resulting in the acceleration of polyP production to respond to the toxic acidic conditions.

Additionally, a mutation in gene ZMO1432 encoding the inner membrane protein component of an RND efflux system containing 12 transmembrane domains [54] was observed in both mutants. The P480L mutation was located at the eleventh transmembrane (TM11) domain, which may play an important role in the process of substrates extrusion from cytoplasm to 
periplasm by proton motive force (PMF) with the conformational changes of RND system [54]. According to the prediction by TMHMM Server v. 2.0 [55], the transmembrane probability of TM11 domain in the mutant protein was improved from 0.7 to 0.95 (Additional file 4: Fig. S2). Therefore, the P480L mutation in ZMO1432 may increase the stability and rigidity of TM11 and hence indirectly improve the efficiency to resist acidic stress by pumping out toxic substances such as organic acids or anions [56].

Moreover, a mutation (A to G) was also found in the intergenic region between $Z M O 1432$ and ZMO1433 in mutant $3.6 \mathrm{M}$ (Table 2), which is in the upstream of the promoter region of ZMO1432 predicted by BPROM [57]. As shown in the RNA-Seq results, the expression of the whole operon encoding an RND efflux system consisted of ZMO1432, ZMO1431, ZMO1430 and $Z M O 1429$ was significantly upregulated at acidic $\mathrm{pH}$ 3.8 in two mutant strains compared with ZM4, and $3.6 \mathrm{M}$ had the highest expression level among these strains (Additional file 1: Table S1, Additional file 3: Table S2). The mutation in the intergenic region in mutant $3.6 \mathrm{M}$ could help upregulate the expression of downstream genes, since the expression of these genes was also upregulated under $\mathrm{pH} 6.2$ in $3.6 \mathrm{M}$ compared with ZM4 (Additional file 3: Table S2). Combining these mutations and transcriptomic results, the RND efflux pump may play a crucial role in acidic-pH resistance in mutant strains.

The last common mutation shared in both mutant strains was within $o x y R$ gene (ZMO1733). OxyR is a LysR family transcriptional regulator consisting of an $\mathrm{N}$-terminal DNA-binding domain (DBD) and a C-terminal regulatory domain (RD), which controls the OxyR regulon consisting of almost 40 genes that can help protect cells from oxidative stress [58]. The T7K mutation in OxyR was in the N-terminal of LysR-type helix-turn-helix (HTH) DNA-binding domain (PS50931, 6-63 aa), which likely changes the binding affinity of $\mathrm{HTH}$ with its target DNA sequence due to the amino acid change from threonine with short side chain to lysine with long side chain (Table 2). Our RNA-Seq results showed that several genes involved in reactive oxygen species (ROS) detoxification possibly regulated by OxyR, such as ZMO0918 (catalase) and ZMO1060 (superoxide dismutase), were significantly upregulated in all strains, especially in ZM4 at $\mathrm{pH} 3.8$ compared to $\mathrm{pH}$ 6.2, while ZMO1211 (glutathione reductase) was significantly upregulated at $\mathrm{pH}$ 3.8 only in wild-type ZM4 (Additional file 3: Table S2). Since acidic $\mathrm{pH}$ could induce a secondary oxidative stress and the acid tolerance response overlaps with the oxidative stress response $[59,60]$, the mutation in oxyR could contribute to the acidic $\mathrm{pH}$ tolerance in mutant strains.
Since mutant strains with these mutations exhibited advantages under acidic- $\mathrm{pH}$ condition compared with wild-type ZM4, these mutations could be crucial for $Z$. mobilis to resist the acidic-pH stress although further investigation is needed to help confirm whether or not and how they are necessary for the acidic-pH resistance phenotype.

\section{Upregulation of genes associated with membrane components for enhanced acidic $\mathrm{pH}$ tolerance}

The modification of the phospholipids in the inner membrane is a strategy to reduce proton permeability, since the lipid composition of cell membrane could be reconfigured at the acidic-pH condition, which will affect proton permeability directly or indirectly [61]. In many bacteria, the resistance to acidic $\mathrm{pH}$ is associated with the conversion of unsaturated fatty acids (UFAs) into cyclopropane fatty acids (CFAs) through the addition of a methyl group to the double bond of UFA, which is associated with cyclopropane fatty acid synthase (Cfa). The expression of $c f a$ gene is usually upregulated under acidic conditions [62, 63], and a similar upregulation was observed for gene ZMO1033 encoding Cfa in ZM4 at acidic $\mathrm{pH}$, suggesting that $c f a$ gene may be associated with outer membrane modification and acidic $\mathrm{pH}$ tolerance (Fig. 5b; Additional file 3: Table S2).

\section{Energy generation through increased glycolysis and energy conservation through decreased cell motility for acidic-pH resistance}

It is reported that Streptococcus mutans altered its metabolism by increasing the glycolytic activity to produce ATP at acidic-pH conditions [64, 65], and ATP utilization was further derived from cell growth for acid tolerance [66]. Although the Entner-Doudoroff (ED) pathway only produces one mole of ATP per single mole of glucose, it is reported that the ED pathway in Z. mobilis is nearly twice as thermodynamically favorable as the Embden-Meyerhof-Parnas (EMP) pathway in E. coli or S. cerevisiae [67]. Our RNA-Seq results demonstrated that four genes involved in the glycolysis pathway, ZMO1478 (pgl), ZMO1240 (gpmA), ZMO1596 (adhB), and ZMO1236 (adhA), were significantly upregulated at the acidic $\mathrm{pH} 3.8$ compared to a neutral $\mathrm{pH} 6.2$ in ZM4 and 3.6M. Another three genes involved in glycolysis pathway, ZMO0997 (eda), ZMO0177 (gap), and $Z M O 0152$ (pyk), were significantly upregulated at $\mathrm{pH} 3.8$ compared to $\mathrm{pH} 6.2$ only in $3.6 \mathrm{M}$. Since these genes are involved in energy generation and recycling, the upregulation of these genes could help produce more ATP for acidic pH tolerance (Fig. 5c; Additional file 3: Table S2). Correspondingly, the final $\log _{2} \mathrm{OD}_{600}$ values of three strains at $\mathrm{pH} 3.8$ were lower than those at $\mathrm{pH}$ 6.2, which 
was about 1.90 and 2.34, respectively (Fig. 4a, c), indicating that more energy was consumed for acidic-pH resistance instead of cell growth. This energy-demanding process might explain the uncoupling between glycolytic and biosynthetic reactions in Z. mobilis [68] with energy generated from glycolysis being diverted for acidic-pH resistance, which is consistent with previous reports that the upregulation of $p y k$ enhanced tolerance against acid stress in S. mutans [65].

In addition, the expression of ZMO1754 encoding SsdA that catalyzes the reaction of acetate biosynthesis from acetaldehyde was significantly upregulated in both mutants and especially wild-type ZM4 at pH 3.8 compared to that at $\mathrm{pH} 6.2$, and was significantly downregulated in mutant background compared to $\mathrm{ZM} 4$ at $\mathrm{pH}$ 3.8 (Fig. 5c; Additional file 3: Table S2). The $s s d A$ gene expression was also correlated with acetate production in mutants and wild-type strains (Additional file 5: Fig. S3). These results indicated that more acetate might be produced at an acidic $\mathrm{pH}$ than at the neutral $\mathrm{pH}$ condition, and acidic-pH-tolerant mutants produced less protonated acetate than wild-type ZM4 in acidic-pH conditions. Therefore, acidic-pH-tolerant mutants could have a less acidified cytoplasmic environment than wild-type ZM4 and could divert $\mathrm{NAD}^{+}$used for acetate production into glycolysis maintaining a low $\mathrm{NADH} / \mathrm{NAD}^{+}$ratio, which was reported to be responsive for acetic acid tolerance in Z. mobilis [31].

Moreover, a number of genes encoding flagellar structure proteins and chemotaxis-related proteins were significantly downregulated under the acidic $\mathrm{pH}$ compared with neutral $\mathrm{pH}$ condition in both $\mathrm{ZM} 4$ and mutant strains (Fig. 5d; Additional file 3: Table S2), which could also help conserve energy from cell motility for survival in conditions of stress such as acidic-pH and ethanol shock [69].

\section{Upregulation of transporter and efflux pump helped maintain $\mathrm{pH}$ homeostasis in acidic conditions}

The increase of acidic end-products such as acetate in acidic-pH conditions (Additional file 5: Fig. S3) could lead to an acidic intracellular condition [64]. Therefore, it is important for cells to export acidic products to maintain intracellular $\mathrm{pH}$ homeostasis. $\mathrm{ABC}$ transporters transport a wide spectrum of substrates from small inorganic and organic molecules to larger organic compounds, and have been confirmed to contribute to acetic acid tolerance as an efflux pump of acetic acid [70]. Our results demonstrated that five genes encoding $\mathrm{ABC}$ transporters (ZMO0143, ZMO1017, ZMO0799-ZMO0801) were significantly upregulated in both mutant strains compared with ZM4 at pH 3.8 (Fig. 5e; Additional file 3: Table S2). Moreover, RND efflux pump is well-known for transporting various compounds including cationic dyes, antibiotics, detergents, and even simple organic solvents with the proton antiport [56, 71, 72]. Our results indicated that an RND efflux pump encoded by ZMO1429$Z M O 1432$ was also significantly upregulated at acidic $\mathrm{pH}$ in both mutant strains compared with ZM4 (Fig. 5e; Additional file 3: Table S2). The upregulation of $A B C$ transporters and efflux pumps may suggest an enhanced capability of mutant strains to maintain cytoplasmic $\mathrm{pH}$ homeostasis under acidic-pH conditions.

In addition, pumping $\mathrm{H}^{+}$out of the cytoplasm is another efficient way to maintain $\mathrm{pH}$ homeostasis [73]. $\mathrm{F}_{1} \mathrm{~F}_{\mathrm{o}}$ ATP synthase $\left(\mathrm{F}_{1} \mathrm{~F}_{\mathrm{o}}\right.$ ATPase $)$ can utilize the proton gradient for ATP synthesis; it can also reverse and hydrolyze ATP to pump $\mathrm{H}^{+}$out to maintain intracellular $\mathrm{pH}$ homeostasis $[74,75]$. For example, genes encoding $F_{1} F_{o}$ ATPase in $S$. mutans were upregulated at acidic $\mathrm{pH}$ to help resist acid stress [76]. Another study indicated that when respiration was impeded, $\mathrm{F}_{1} \mathrm{~F}_{\mathrm{o}}$ ATPase hydrolyzed ATP to pump protons and contributed to the intracellular neutral condition maintaining the essential mitochondrial membrane potential [77]. Our results demonstrated that 7 genes encoding $\mathrm{F}_{1} \mathrm{~F}_{\mathrm{o}}$ ATP synthase $(Z M O 0239$, ZMO0240, ZMO0241, ZMO0667, ZMO0668, ZMO0669, $Z M 00671)$ and another gene encoding $\mathrm{F}_{1} \mathrm{~F}_{\mathrm{o}}$ ATP synthase assembly protein (ZMO2005) were significantly upregulated at $\mathrm{pH} 3.8$ compared to $\mathrm{pH} 6.2$ for the mutant strain 3.6M (Fig. 5f; Additional file 3: Table S2). Since the cellular respiration process was uncoupled with cell growth in Z. mobilis [78], and the ATP generation was majorly from glycolysis whose activity was increased as discussed above, the upregulation of $F_{1} F_{0}$ ATPase genes may possibly help pump $\mathrm{H}^{+}$out from the cytoplasm through consuming ATP.

Furthermore, proton translocation was suggested to result in an alkalization of the intracellular medium in Z. mobilis at $\mathrm{pH} 6.5$ during the respiration by transferring the $\mathrm{H}^{+}$out of cytoplasm [79]. Two genes related to the respiration chain for transferring electrons to oxygen, ZMO0012 and ZMO0568, were downregulated significantly; and six other genes, ZMO0956-ZMO0958, $Z M O 0961, Z M O 1253$ and $Z M O 1255$, were reduced more than 1.5 times in $\mathrm{ZM} 4$ at $\mathrm{pH} 3.8$ compared with $\mathrm{pH} 6.2$ (Fig. 5f; Additional file 3: Table S2). In addition, six genes encoding Rnf complex (ZMO1809-ZMO1814) and an assembly gene $(Z M O 1808)$ were also downregulated at pH 3.8 compared with pH 6.2 in ZM4 but not in mutant strains (Fig. 5f; Additional file 3: Table S2). The Rnf complex is required for the electron transfer to nitrogenase during nitrogen fixation with proton excretion in Rhodobacter capsulatus [80]. Furthermore, the gene ZMO0456 encoding the ferredoxin, which is the electron acceptor from $\mathrm{NADH}$ and electron donor for nitrogenase, was also 
downregulated at acidic $\mathrm{pH} 3.8$ compared with neutral pH 6.2 in ZM4 (Fig. 5f; Additional file 3: Table S2). The downregulation of genes associated with the electron transfer chain at the acidic-pH condition in wild-type ZM4 could make the excretion of protons against proton gradient from cytoplasm difficult, leading to growth inhibition. In contrast, the expression of these genes in the mutant background was not significantly downregulated at acidic $\mathrm{pH} 3.8$ compared with neutral $\mathrm{pH}$ 6.2. Instead, they were upregulated compared with $\mathrm{ZM} 4$ at $\mathrm{pH} 3.8$ (Fig. 5f; Additional file 3: Table S2). These results indicated that mutants could maintain relatively high proton transportation capacity against acidic-pH conditions.

\section{Proton consumption and alkaline compound production for enhanced acidic- $\mathrm{pH}$ resistance}

Biosynthesis of branched-chain amino acids (BCAAs) was reported to reduce $\mathrm{H}^{+}$concentration in the cytoplasm by consuming proton or producing ammonia [64]. Two genes involved in the conversion of isoleucine from threonine in Z. mobilis (ZMO0687 and ZMO0115) were significantly upregulated in mutants $3.5 \mathrm{M}$ and $3.6 \mathrm{M}$ compared with ZM4 at pH 3.8 (Fig. 5G; Additional file 3: Table S2).

In addition, gene ZMO0296 encoding adenosine deaminase (Ada) to convert adenosine into inosine with ammonia production was significantly upregulated at pH 3.8 in 3.6M strains compared with ZM4 (Fig. 5g; Additional file 3: Table S2). The expression of ZMO1207 gene encoding nitrilase (Nit, EC 3.5.5.1) that catalyzes the substrate containing cyano group to ammonia was also upregulated at $\mathrm{pH} 3.8$ in mutant strain $3.6 \mathrm{M}$ compared with ZM4 (Fig. 5g; Additional file 3: Table S2). At acidic $\mathrm{pH}$ conditions, ammonia could react with protons to produce the ammonium ion [81], which indicated that mutant strain $3.6 \mathrm{M}$ possessed greater capacity than mutant strain $3.5 \mathrm{M}$ and ZM4 to neutralize the intracellular $\mathrm{pH}$ by proton-consuming and alkali-producing reactions resulting in enhanced acidic-pH resistance.

However, the cytoplasmic $\mathrm{pH}$ homeostasis is connected with the proton motive force (PMF), which consists of two components of a transmembrane $\mathrm{pH}$ gradient $(\Delta \mathrm{pH})$ and a transmembrane electrical potential $(\Delta \psi)$ maintaining intercellular negative relative to outside [81]. The production of $\mathrm{NH}_{4}{ }^{+}$from $\mathrm{NH}_{3}$ and proton thus will result in excess intracellular positive charges while reducing the $\Delta \mathrm{pH}$, which could destroy the PMF and impair cellular functions. To balance the excess intracellular positive charges, exporting $\mathrm{NH}_{3}$ and $\mathrm{NH}_{4}{ }^{+}$by an ammonium transporter would avoid excessive positive charges hyperpolarizing the cell membrane [81]. Our RNA-Seq results showed that the transcriptional level of ammonium transporter encoded by ZMO0346 was upregulated significantly in both mutant strains compared with ZM4 (Fig. 5g; Additional file 3: Table S2), which may help transport $\mathrm{NH}_{3}$ and $\mathrm{NH}_{4}{ }^{+}$outside the cell and ensure normal PMF function on the membrane. Moreover, it was reported that the conversion of $\mathrm{CO}_{2}$ to $\mathrm{HCO}_{3}{ }^{-}$by carbonate anhydrase (CA) also contributed to acid-base equilibrium in $H$. pylori [21, 81]. It is interesting that the transcriptional level of ZMO1133 encoding carbonate anhydrase was significantly upregulated at $\mathrm{pH} 3.8 \mathrm{com}-$ pared to that at $\mathrm{pH} 6.2$ in all strains (Fig. 5g; Additional file 3: Table S2). Since $Z$. mobilis can consume sugars and produce $\mathrm{CO}_{2}$ efficiently [82], $\mathrm{CO}_{2} / \mathrm{HCO}_{3}{ }^{-}$could also be involved in keeping acid-base equilibrium at acidic- $\mathrm{pH}$ conditions.

\section{Reduced energy consumption on macromolecular repair for enhanced acidic $\mathrm{pH}$ tolerance of mutant strains}

Cell membrane, proteins, and DNA would be damaged when bacteria are cultured in acidic environments. To reduce the damage, the expression of repair and defense proteins such as DnaK, RecA, UvrA, IrrE, and AP endonuclease could be increased to protect the macromolecules from the damage $[64,75,83]$. Our results showed that the transcription level of ZMO0660 (dnaK) together with its co-chaperone $Z M O 1690($ dnaJ) as well as ZMO1588 (uvrA) and its subunit ZMO0362 (uvrB) were upregulated in $\mathrm{ZM} 4$ at acidic $\mathrm{pH} 3.8$ than at neutral $\mathrm{pH}$ 6.2. Moreover, the expression level of Clp protease complex, ZMO0405 (clpA), ZMO0948 (clpP), ZMO0949 $(c l p X)$ and $Z M O 1424(c l p B)$ involved in protein remodeling and reactivation [64, 84], altered similarly as ZMO0660 (Fig. 5h; Additional file 3: Table S2). These results demonstrated that it is necessary to enhance the expression of these proteins in order to protect DNA and protein from damage in acidic cytoplasm.

However, the expression level of these genes was downregulated at $\mathrm{pH} 3.8$ in mutants compared to ZM4, except for gene $r e c A$, which had no significant changes at different $\mathrm{pH}$ conditions in any strains. In addition, the transcriptional level of ZMO1929, which encodes GroEL protein and is important during adaptation to acid [64], was downregulated at $\mathrm{pH} 3.8$ in mutant strains compared to ZM4 (Fig. 5h; Additional file 3: Table S2). The deficient in HtrA, a surface protease involved in the degradation of aberrant proteins, reduced the ability of the mutant strain to endure acidic conditions [85], which demonstrated that this protein is important for cells to defend acid conditions.

The phenomenon that the expression of macromolecular repair genes that are indispensable for acid resistance was upregulated at acidic $\mathrm{pH}$ only in wild-type ZM4 background indicated that a great demand on these proteins is needed for ZM4 to survive at acidic-pH 
conditions, while the downregulation of these genes in mutant backgrounds compared with ZM4 suggested that acidic-pH-tolerant mutants may acquire the capability to manage defense responses without triggering abrupt augmented macromolecular repair activities and thus conserve energy for cell growth instead.

\section{Genetic confirmation of genes associated with acidic-pH resistance in Z. mobilis ZM4}

To evaluate the impact of candidate genes associated with acidic-pH resistance identified through our genomic and transcriptomic studies as discussed above, six plasmids containing candidate operons were constructed based on the shuttle vector pEZ15Asp with Ptet as the promoter [86]. These candidate operons including ZMO0142-ZMO0145 encoding ABC transporter, ZMO0798-ZMO0801 encoding multiple drug efflux, ZMO0956-ZMO0958 encoding cytochrome bc1 complex, ZMO0238-ZMO0242 encoding ATP synthesis $\mathrm{F}_{1}$ submits, $Z M O 1428-Z M O 1432$ encoding RND efflux system with a mutation in $Z M O 1432$, and $Z M O 2005$, $Z M 00667-Z M O 0671$ encoding ATP synthesis $\mathrm{F}_{0}$ submits were cloned into pEZ15Asp shuttle vector, which were named pEZ-Tc1, pEZ-Tc2, pEZ-Tc3, pEZ-Tc4, pEZ-Tc5(M) and pEZ-Tc6, respectively. These plasmid constructs including the empty vector pEZ15Asp as the control were then introduced into ZM4 separately. These recombinant strains were then investigated under different conditions to examine their impact on cell growth (Fig. 6, Additional file 6: Fig. S4).

With the increase of the tetracycline inducer concentration from 0 to $0.8 \mu \mathrm{g} / \mathrm{mL}$, the growth advantage of the recombinant strain containing pEZ-Tc3 decreased at $\mathrm{pH} 3.8$ (Fig. 6a, b). Our previous work demonstrated that the Ptet promoter driving the operon expression used in this study is leaky even when tetracycline was a

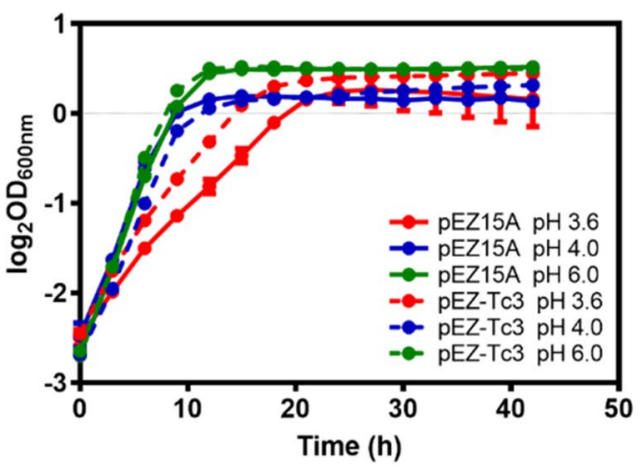

c

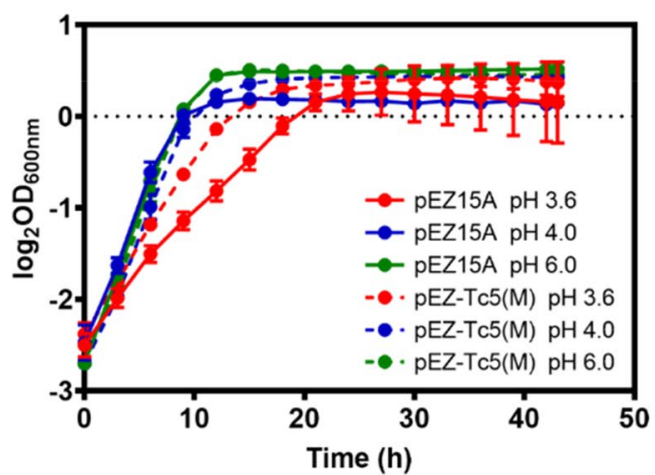

b

pEZ-Tc3 and pEZ15A

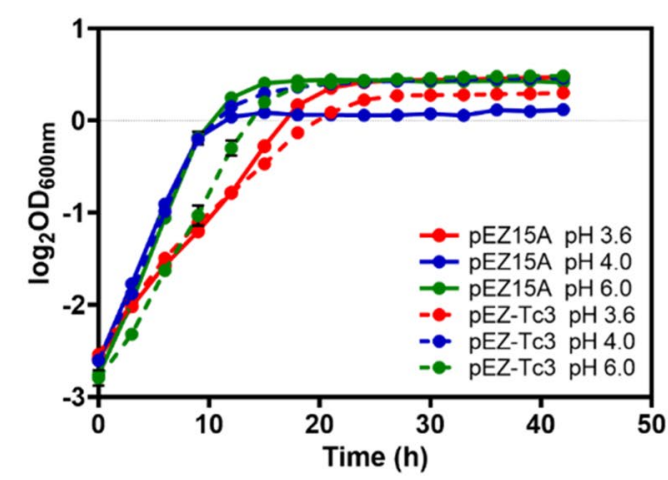

d pEZ-Tc5 (M) and pEZ15A (Tc, $0.8 \mu \mathrm{g} / \mathrm{mL}$ )

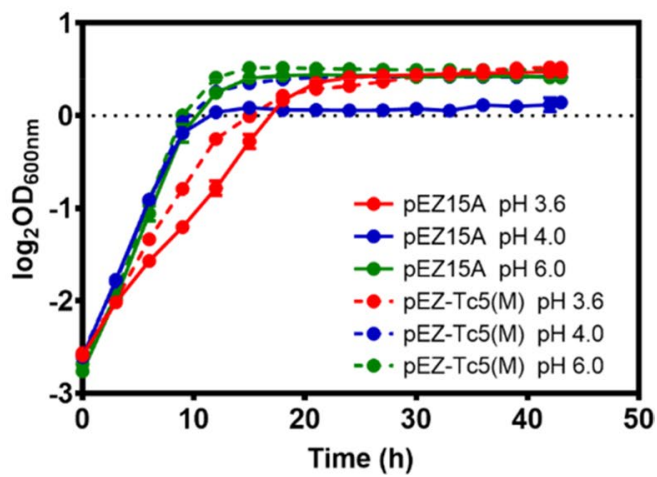

Fig. 6 Cell growth of recombinant and wild-type strains of Z. mobilis containing the control plasmid pEZ15A and plasmid constructs of pET-Tc3 and pET-Tc5 (M) at pH 3.6, 4.0, and 6.0 without tetracycline $(\mathbf{a}, \mathbf{c})$ and with $0.8 \mu \mathrm{g} / \mathrm{mL}$ tetracycline induction $(\mathbf{b}, \mathbf{d})$. pEZ-Tc3, plasmid construct expressing operon ZMO0956-ZMO0958 encoding cytochrome bc1 complex; pEZ-Tc5 (M), plasmid construct expressing operon ZMO1428-ZMO1432 encoding RND efflux system with a mutation in ZMO1432. At least two independent experiments were performed with similar results. Values are the mean of one representative experiment with three technical replicates. Error bars represent standard deviations 
not supplemented into the medium [86, 87]. Therefore, this result suggested that the cytochrome bc1 complex encoded by the operon ZMO0956-ZMO0958 in the recombinant strain containing pEZ-Tc3 could contribute to the acidic $\mathrm{pH}$ tolerance in $Z$. mobilis at a low expression level, which is consistent with our RNA-Seq result that the reduced expression of genes associated with electron transfer chain impacted the acid resistance of wildtype ZM4 (Fig. 5f; Additional file 3: Table S2). In addition, the upregulated expression of cytochrome bc1 complex impacted the growth in neutral pH condition (Fig. 6b), which may indicate a potential role of low expression of this "dead-end" respiration branch in cell growth, since the function of cytochrome bc1 in electron transport is still unknown in Z. mobilis [88]. Similarly, with the increase of tetracycline inducer concentration from 0 to $0.8 \mu \mathrm{g} / \mathrm{mL}$, the growth advantage of recombinant strain containing pEZ-Tc5(M) decreased in acidic-pH condition, but there was still an advantage with $0.8 \mu \mathrm{g} / \mathrm{mL}$ tetracycline (Fig. 6c, d), which is again consistent with the upregulation of these genes in our RNA-Seq study (Fig. 5e; Additional file 3: Table S2). Although further investigation is still needed to understand the association of acidic-pH resistance with the different expression levels of these genes, our result suggested that the mutation in the intergenic region of upstream of ZMO1432 in mutant $3.6 \mathrm{M}$ may contribute to the upregulation of the downstream gene, and a higher expression of RND efflux pump is more advantageous for strains to defend against acidic-pH conditions.

Recombinant strains containing the other four operons had no advantageous effect on cell growth in acidic-pH conditions both with and without tetracycline induction (Additional file 6: Fig. S4). Instead, the growth of the recombinant strain containing $\mathrm{pEZ}-\mathrm{Tc} 2$ was dramatically impeded when induced with $0.8 \mu \mathrm{g} / \mathrm{mL}$ tetracycline (Additional file 6: Fig. S4C, S4D), and the growth of the recombinant strain containing pEZ-Tc6 was inhibited both with and without the supplementation of tetracycline inducer (Additional file 6: Fig. S4G, S4H). Since these operons encode the $A B C$ transporter, multiple drug efflux, and ATP synthase submits, which may function with other cellular component coordinately, a delicate balance of these operons with other genes may be needed for acidic-pH resistance similar to a previous report's findings that the tailored expression of multiple genes simultaneously was essential for enhanced low-pH tolerance in E. coli [89].

In summary, although our results suggested that the mutation in the intergenic region of upstream of ZMO1432 in mutant $3.6 \mathrm{M}$ may contribute to the upregulation of the downstream gene (Table 2), and high expressions of RND efflux pump or cytochrome bc1 complex is advantageous for the strain to defend acidic$\mathrm{pH}$ condition (Fig. 6), the advantage of these recombinant strains was still not as prominent as the mutant itself. This indicates that one gene/operon is not sufficient to warrant the acidic $\mathrm{pH}$ tolerance, and synergetic effects of multiple mutations affecting protein structural changes and expression of multiple genes need to be further investigated to understand the association of acidic-pH resistance phenotype with the genetic difference of mutant strains.

\section{Conclusion}

Two acidic-pH-tolerant mutants $3.6 \mathrm{M}$ and $3.5 \mathrm{M}$ of Z. mobilis, which possessed advantages at acidic-pH conditions including high growth rate and ethanol productivity, were obtained from wild-type ZM4 by ALE strategy in this study. Genetic changes and gene expression at acidic and neutral $\mathrm{pH}$ conditions were then investigated using NGS-based genome resequencing and RNA-Seq with the underlying mechanism of acidic-pH resistance proposed. Specifically, Z. mobilis altered its metabolic flux through genomic changes affecting gene and gene expression associated with membrane modification, proton transportation, energy conservation and redistribution for acidic- $\mathrm{pH}$ resistance. Mutant strains had genes differentially expressed at acidic-pH conditions to help strengthen membraneassociated transporters, and increase proton consumption and alkaline metabolite production to maintain proton permeability and cellular $\mathrm{pH}$ homeostasis.

In addition, the enhanced $\mathrm{F}_{1} \mathrm{~F}_{\mathrm{o}}$ ATPase was also upregulated in mutant $3.6 \mathrm{M}$, which could contribute to its advantage in the acidic- $\mathrm{pH}$ condition over another mutant 3.5M and wild-type ZM4. Genetic study results demonstrated that the introduction of plasmid constructs containing operons expressing cytochrome bc1 complex or RND efflux pump affected acidic $\mathrm{pH}$ tolerance in $Z$. mobilis. This study obtained and characterized acidic-pH resistant mutant strains of $Z$. mobilis, which can be used as candidate strains for commercial bioethanol production under acidic fermentation conditions. In addition, the molecular mechanism of acidic $\mathrm{pH}$ tolerance of $Z$. mobilis proposed in this study can also facilitate future research on rational design of synthetic microorganisms with enhanced tolerance against acidic-pH conditions, and the strategy we developed in this study combining ALE, genome resequencing, RNA-Seq, and classical genetic study for mutant evolution and characterization can be applied to other industrial microorganisms. 


\section{Materials and methods}

\section{Bacterial strain and culture conditions}

Escherichia coli DH5 $\alpha$ from Invitrogen (USA), was cultured in Lysogeny Broth (LB, $10 \mathrm{~g} / \mathrm{L} \mathrm{NaCl}, 10 \mathrm{~g} / \mathrm{L}$ tryptone, $5 \mathrm{~g} / \mathrm{L}$ yeast extract, and $1.5 \%$ agar for solid). Z. mobilis ZM4 (ATCC 31821) was cultured in Rich Medium (RM, $10 \mathrm{~g} / \mathrm{L}$ yeast extract, $2 \mathrm{~g} / \mathrm{L} \mathrm{KH}_{2} \mathrm{PO}_{4}$, different concentration of glucose as required, and $1.5 \%$ agar for solid) at $30{ }^{\circ} \mathrm{C}$ with sharking at $100 \mathrm{rpm}$. The initial $\mathrm{pH}$ of culture medium was adjusted using $\mathrm{HCl}$ or $\mathrm{KOH}$. For $\mathrm{pH}$ tolerance tests, glucose concentration in the media was $20.0 \mathrm{~g} / \mathrm{L}$ (RMG2) and $50.0 \mathrm{~g} / \mathrm{L}$ (RMG5); a flask containing RMG of its $80 \%$ volume (e.g., $400 \mathrm{~mL}$ RMG in a $500-\mathrm{mL}$ flask) was used for shake-flask fermentation experiments.

\section{Adaptive laboratory evolution (ALE)}

ALE was applied to evolve the wild-type strain Z. mobilis ZM4 (Fig. 2a). Cells were first streaked on RMG2 plate from stock; two colonies were then selected randomly and cultivated in liquid RMG2. After grown to the mid-exponential phase $\left(\mathrm{OD}_{600}=0.80-2.50\right)$ as determined by a spectrophotometer UV-1800 (AOE, China), cells were then transferred into fresh RMG2 at $\mathrm{pH} 4.0$ with the initial $\mathrm{OD}_{600}$ value of 0.1 . When reaching to the mid-exponential phase, strains were transferred again into the same medium. After 30 cycles of cultivation at $\mathrm{pH} 4.0$, the adapted strains were further transferred to fresh medium at $\mathrm{pH} 3.5$ or $\mathrm{pH}$ 3.6. Finally, four evolved strains with enhanced tolerance to acidic $\mathrm{pH}$ were obtained, two adapted with 55 cycles of cultivation at $\mathrm{pH} 3.5$ and the other two with 75 cycles of cultivation at $\mathrm{pH} 3.6$ (Fig. 2a).

\section{Stability and $\mathrm{pH}$ tolerance evaluation of evolved cultures using Bioscreen $\mathrm{C}$}

Four evolved cultures were streaked on RMG2 plate, three colonies were then selected randomly and cultured overnight in $2 \mathrm{~mL}$ liquid RMG2 to the exponential phase. Seed cultures were washed twice and transferred into different media with an initial $\mathrm{OD}_{600 \mathrm{~nm}}$ value of 0.1 . Media were adjusted to $\mathrm{pH} 3.6$ for the stability analysis or adjusted to $\mathrm{pH} 3.5, \mathrm{pH} 3.6, \mathrm{pH} 4.0$, and $\mathrm{pH} 6.0$, respectively, for the $\mathrm{pH}$ tolerance analysis. Cell growth was monitored at $600 \mathrm{~nm}$ using a Bioscreen $\mathrm{C}$ instrument (Growth Curves USA, NJ) with three technical replicates [90]. The working volume was $200 \mu \mathrm{L} /$ well. The temperature was controlled at $30{ }^{\circ} \mathrm{C}$ and the absorbance values were automatically read at regular intervals of $15 \mathrm{~min}$. The experiments were repeated at least twice.

\section{Cell growth and fermentation analysis}

Fermentations were performed in $500-\mathrm{mL}$ shake flasks with $400 \mathrm{~mL}$ RMG5 at $30{ }^{\circ} \mathrm{C}$ with an agitation rate of $100 \mathrm{rpm}$, and the wild-type ZM4 was used as the control. The $\mathrm{pH}$ of the media was adjusted at 3.8 and 6.2 by automatic titration with $\mathrm{HCl}$ and $\mathrm{KOH}$. During the fermentation, Cell growth was determined every $2 \mathrm{~h}$ by measuring the optical density at $600 \mathrm{~nm}\left(\mathrm{OD}_{600}\right)$ using spectrophotometer (UV-1800, AOE, Chain). The samples were also collected and centrifuged at 10,000 rpm for $5 \mathrm{~min}$, and filtered through $0.22-\mu \mathrm{m}$ filters. Samples at the exponential phase were harvested for genome resequencing and RNA-Seq. Glucose and ethanol in filtered supernatants were analyzed using high-pressure liquid chromatography (HPLC, LC-20 AD, refractive index detector RID-10A, Shimadzu, Kyoto, Japan) with an Aminex HPX-87H column (Bio-Rad, Hercules, CA, USA) at $60{ }^{\circ} \mathrm{C}$ at the flow rate of $0.5 \mathrm{~mL} / \mathrm{min}$ using $5 \mathrm{mM} \mathrm{H}_{2} \mathrm{SO}_{4}$ as the mobile phase.

\section{Whole-genome resequencing analysis}

Whole-genome resequencing was performed using the paired-end sequencing technology according to standard Illumina protocols by IgeneCode, Inc., Beijing, China. The paired-end reads quality was checked using FastQC program (http://www.bioinformatics.babra ham.ac.uk/projects/fastqc/). Data passing the quality control were then mapped to the reference genome sequences of Z. mobilis ZM4, ATCC 31821 (GenBank accession No. of chromosome: NZ_CP023715, and plasmids: NZ_CP023716, NZ_CP023717, NZ_ CP023718, NZ_CP023719) using the CLC Genomics Workbench (version 11.0) to identify the genomic variations. The objective mutations of the mutant strains were obtained with the parental wild-type strain as control, of which the mutation frequency more than $30 \%$ was filtered.

\section{RNA-Seq transcriptomic analysis}

The transcriptomic study was carried out as reported previously $[45,91]$. Briefly, cell cultures were collected at the mid-log phase under different $\mathrm{pH}$ conditions, followed by total RNA extraction using TRIzol reagent (Invitrogen, USA). rRNA within total RNA was depleted using Ribo-off rRNA Depletion Kit (Bacteria NR407). The fragmentation buffer was then added for interrupting mRNA to short fragments, and random hexamer-primers were used to synthesize the firststrand cDNA. The second-strand cDNA was synthesized using buffer, dATPs, dGTPs, dCTPs, dUTPs, RNase $\mathrm{H}$ and DNA polymerase $\mathrm{I}$, respectively, after removing dNTPs. The fragments were connected 
with sequencing adapters for sequencing library construction, which was then sequenced using Illumina NovaSeq 6000 System.

Data passing the quality control were imported into CLC Genomics Workbench (version 11.0) for RNASeq analysis to get the RPKM values with $Z$. mobilis ZM4, ATCC 31821 (GenBank accession No. of chromosome: NZ_CP023715, and plasmids: NZ_CP023716, NZ_CP023717, NZ_CP023718, NZ_CP023719) and four related plasmids as the reference genome. Gene expression normalization, analysis of variance (ANOVA), and hierarchical clustering analysis were conducted using JMP Genomics (version 9.0) to identify differentially expressed genes at different conditions. Significantly differential expression genes were determined with a selection threshold of $P$-value $\leq 0.01$ and $\log _{2}$-fold change $\geq 1$ (significant induction) or $\leq-1$ (significant repression). Duplicate samples were used for each condition.

\section{Genetic study evaluating the impact of candidate operons on acidic $\mathrm{pH}$ tolerance}

Six operon candidates, ZMO0142-ZMO0145, ZMO0798-ZMO0801, Z ZMO0956-ZMO0958, ZMO0238-ZMO0242, ZMO1429-ZMO1432, ZMO2005 with $Z M O 0667-Z M O 0671$, encoding $\mathrm{ABC}$ transporter related protein, multiple drug efflux, cytochrome bc1 complex, ATP synthesis $F_{1}$ submits, RND efflux pump, ATP synthesis $F_{0}$ submits, were amplified from the genomic DNA of Z. mobilis except that ZMO1429$Z M O 1432$ was amplified from the genomic DNA of mutant strain with a mutation on the gene ZM01432 using primers listed in Additional file 7: Table S3. The PCR products were then cloned into the pEZ15Asp shutter vector with Ptet as the promoter [86] by the Gibson assembly method [92]. Each primer for operon amplification contained a 15 20 nucleotide overlapping region of the vector. Recombinant strains containing correct plasmid constructs were identified by colony PCR and confirmed by Sanger sequencing (Tsingke, China). These plasmids were named as pEZ-Tc1, pEZ-Tc2, pEZ-Tc3, pEZ-Tc4, pEZ-Tc5(M), and pEZ-Tc6, respectively.

The correct plasmids were then transformed into $Z$. mobilis competent cells via electroporation $(0.1-\mathrm{cm}$ electrode gap, $1600 \mathrm{~V}, 200 \Omega, 25 \mu \mathrm{F})$ using a Gene Pulser ${ }^{\circledR}$ (Bio-Rad, USA) as described previously [93]. Candidate strains containing correct plasmid construct were identified by colony PCR, and confirmed by Sanger sequencing (Tsingke, China). Cell growth of these strains was evaluated at different pHs $(3.6,4.0,6.0)$ in RMG5 medium using Bioscreen $\mathrm{C}$. Tetracycline was added at concentrations of $0.4 \mu \mathrm{g} / \mathrm{mL}$ and $0.8 \mu \mathrm{g} / \mathrm{mL}$ to induce genes expression.

\section{Supplementary information}

Supplementary information accompanies this paper at https://doi. org/10.1186/s13068-020-01781-1.

\section{Additional file 1: Table S1. List of all significantly differentially expressed genes between different strains in different conditions. $P$ is $-\log 10$ (P-value).}

Additional file 2: Fig. S1. The Venn diagrams of significantly differentially expressed genes of same strain under different $\mathrm{pH}$ conditions (A) and two different strains at acidic $\mathrm{pH}$ condition (B).

Additional file 3. Table $\mathbf{S 2}$. List of significantly differentially expressed genes in different functional categories comparing same strain at different conditions or different strains under low $\mathrm{pH}$. $P$ is $-\log 10$ ( $P$-value). NS, not significantly differentially expressed.

Additional file 4: Fig. S2. The transmembrane domain prediction of the inner membrane component of RND efflux system without mutation (A) and with mutation (B) using TMHMM. The arrow points the T11 domain, where the mutation located.

Additional file 5: Fig. S3. Acetate production of Z. mobilis wild-type ZM4 and mutant strains of $3.5 \mathrm{M}$ and $3.6 \mathrm{M}$ at pH 3.8 and 6.2 when the glucose was completely consumed. At least two independent experiments were performed with similar results. Values are the mean of one representative experiment with three technical replicates. Error bars represent standard deviations. Statistics analysis was calculated using one-way ANOVA by GraphPad Prism 8.3.0. ${ }^{* *}$ indicates adjusted $p$-value $<0.01$.

Additional file 6: Fig. S4. Cell growth of recombination strains and wild type of Z. mobilis containing the control plasmid pEZ15A and plasmid constructs of pEZ-Tc1, pEZ-Tc2, pEZ-Tc4, and pEZ-Tc6, respectively, at $\mathrm{pH} 3.6,4.0,6.0$ without tetracycline induction $(\mathbf{A}, \mathbf{C}, \mathbf{E}, \mathbf{G})$, or with the induction of $0.8 \mu \mathrm{g} / \mathrm{mL}$ tetracycline (B, D, F, H). In these graphs, red line represents $\mathrm{pH}$ 3.6, blue line represents $\mathrm{pH}$ 4.0, green line represents $\mathrm{pH} 6.0$ (solid line represents pEZ15A and dotted line represents pEZ-Tc1, pEZ-Tc2, pEZ-Tc4 or pEZ-Tc6, respectively). pEZ-Tc1, plasmid construct expressing operon ZMO0142-ZMO0145 encoding ABC transporter related protein; pEZ-Tc2, plasmid construct expressing operon ZMO0798-ZMO0801 encoding multiple drug efflux related proteins; $\mathbf{p E Z - T c 4}$, plasmid construct expressing operon ZMO0238 ZMO0242 encoding ATP synthesis $F_{1} F_{0}$ submits; pEZ-Tc6, plasmid construct expressing operon ZMO2005, ZMO0667ZMO0671 encoding ATP synthesis $F_{1} F_{0}$ submits. Experiments have been repeated at least three times with similar result, and results from one experiment with three triplicate technical repeats were presented.

Additional file 7: Table S3: Primers used in this study.

\section{Abbreviations}

ABC: ATP-binding cassette; ADA: Adenosine deaminase; ALE: Adaptive laboratory evolution; ANOVA: Analysis of variance; BCAAs: Branched-chain amino acids; CA: Carbonate dehydratase; CDS: Coding sequence; CFAs: Cyclopropane fatty acids; DBD: DNA-binding domain; DEGs: Expressed genes; ED pathway: Entner-Doudoroff pathway; EMP pathway: Embden-Meyerhof-Parnas pathway; GRAS: Generally regarded as safe; HPLC: High-pressure liquid chromatography; HTH: Helix-turn-helix; LB: Lysogeny broth; mARTP: Multi-round atmospheric and room temperature plasma; NGS: Next-generation sequencing; NIT: Nitrilase; NTG: Nitrosoguanidine; PCR: Polymerase chain reaction; PMF: Proton motive force; polyP: Polyphosphate; PBP: Proton-buffering peptide; RD: Regulatory domain; RM: Rich medium; RNA-Seq: RNA sequencing; RND: Resistance nodulation-cell division; ROS: Reactive oxygen species; SNPs: Single-nucleotide polymorphisms; SNVs: Single-nucleotide variants; TM: Transmembrane; UFAs: Unsaturated fatty acids; WGR: Whole-genome resequencing; $\Delta \mathrm{pH}$ : pH gradient; $\Delta \psi:$ Transmembrane electrical potential.

\section{Acknowledgements}

We thank Mengyue Qiu from Hubei University for her support with HPLC technology, and appreciate the assistance of Prof. Li Yl and Jessey Yang for manuscript editing and insightful discussions. 


\section{Authors' contributions}

SY conceived and designed the experiments with inputs from all authors. QY evolved strains and tested the fermentation with the help from SW, YT, YZ and JG. YY handled and analyzed the high-throughput sequencing data. QY, YY, $W X, Y C$ and SY prepared figures and tables, and wrote the manuscript. QY, YY, XW, YC, MH, BW, SC and SY discussed and revised the manuscript. All authors contributed to data analyses, revised the final manuscript. All authors read and approved the final manuscript.

\section{Funding}

This work was supported by the National Key Research and Development Program of China (2018YFA090039), National Science Foundation of China (21978071, U1932141), the Leading Innovative and Entrepreneur Team Introduction Program of Zhejiang Province (2018R01014) and the Technical Innovation Special Fund of Hubei Province (2019AHB055, 2018ACA149). We also acknowledge the support from State Key Laboratory of Biocatalysis and Enzyme Engineering (Hubei University).

\section{Availability of data and materials}

The authors declare that all data supporting the findings of this study are available within the paper and its Supplemental files or from the corresponding author on request. The raw data of genome resequencing and RNA-Seq were deposited into Sequence Read Archive (SRA) database with the BioProject accession numbers of PRJNA590883 and PRJNA644990, respectively.

\section{Ethics approval and consent to participate}

The authors declare that this study does not involve human subjects, human material and human data.

\section{Consent for publication}

All authors read and approved the final manuscript.

\section{Competing interests}

The authors declare that they have a patent application associated with mutant strains developed in this study.

\section{Author details}

${ }^{1}$ State Key Laboratory of Biocatalysis and Enzyme Engineering, Environmental Microbial Technology Center of Hubei Province and School of Life Sciences, Hubei University, Wuhan 430062, China. ${ }^{2}$ Key Laboratory of Development and Application of Rural Renewable Energy, Biomass Energy Technology Research Centre, Biogas Institute of Ministry of Agriculture, South Renmin Road, Chengdu 610041, China.

Received: 3 March 2020 Accepted: 4 August 2020

Published online: 13 August 2020

\section{References}

1. Yang S, Franden MA, Yang Q, Chou YC, Zhang M, Pienkos PT. Identification of inhibitors in lignocellulosic slurries and determination of their effect on hydrocarbon-producing microorganisms. Front Bioeng Biotechnol. 2018;6:23

2. Agarwal AK. Biofuels (alcohols and biodiesel) applications as fuels for internal combustion engines. Progr Energy Combust Sci. 2007;33(3):233-71.

3. Mills TY, Sandoval NR, Gill RT. Cellulosic hydrolysate toxicity and tolerance mechanisms in Escherichia coli. Biotechnol Biofuels. 2009;2:26.

4. Hahn-Hagerdal B, Galbe M, Gorwa-Grauslund MF, Liden G, Zacchi G. Bio-ethanol-the fuel of tomorrow from the residues of today. Trends Biotechnol. 2006:24(12):549-56.

5. Zabed H, Sahu JN, Boyce AN, Faruq G. Fuel ethanol production from lignocellulosic biomass: an overview on feedstocks and technological approaches. Renew Sust Energ Rev. 2016;66:751-74.

6. Balat M, Balat $\mathrm{H}, \mathrm{Öz}$ C. Progress in bioethanol processing. Prog Energy Combust Sci. 2008;34(5):551-73.

7. Zhang W, Geng A. Improved ethanol production by a xylose-fermenting recombinant yeast strain constructed through a modified genome shuffling method. Biotechnol Biofuels. 2012;5(1):46.
8. Erdei B, Barta Z, Sipos B, Reczey K, Galbe M, Zacchi G. Ethanol production from mixtures of wheat straw and wheat meal. Biotechnol Biofuels. 2010;3(1):16.

9. Ohgren K, Bengtsson O, Gorwa-Grauslund MF, Galbe M, Hahn-Hagerdal B, Zacchi G. Simultaneous saccharification and co-fermentation of glucose and xylose in steam-pretreated corn stover at high fiber content with Saccharomyces cerevisiae TMB3400. J Biotechnol. 2006;126(4):488-98.

10. Matsushika A, Negi K, Suzuki T, Goshima T, Hoshino T. Identification and characterization of a novel Issatchenkia orientalis GPI-anchored protein, logas 1, required for resistance to low $\mathrm{pH}$ and salt stress. PLOS ONE. 2016;11(9):e0161888

11. Mira NP, Teixeira MC, Sa-Correia I. Adaptive response and tolerance to weak acids in Saccharomyces cerevisiae: a genome-wide view. OMICS. 2010;14(5):525-40.

12. Nwuche CO, Murata Y, Nweze JE, Ndubuisi IA, Ohmae H, Saito M, Ogbonna JC. Bioethanol production under multiple stress condition by a new acid and temperature tolerant Saccharomyces cerevisiae strain LC 269108 isolated from rotten fruits. Process Biochem. 2018:67:105-12.

13. Brexó RP. Sant'Ana AS: impact and significance of microbial contamination during fermentation for bioethanol production. Renew Sust Energ Rev. 2017;73:423-34.

14. Ma H, Wang Q, Qian D, Gong L, Zhang W. The utilization of acid-tolerant bacteria on ethanol production from kitchen garbage. Renew Energ. 2009;34(6):1466-70

15. Tao F, Miao JY, Shi GY, Zhang KC. Ethanol fermentation by an acid-tolerant Zymomonas mobilis under non-sterilized condition. Process Biochem. 2005:40(1):183-7.

16. Djoko KY, Phan MD, Peters KM, Walker MJ, Schembri MA, McEwan AG. Interplay between tolerance mechanisms to copper and acid stress in Escherichia coli. Proc Natl Acad Sci USA. 2017;114(26):6818-23.

17. Noh MH, Lim HG, Woo SH, Song J, Jung GY. Production of itaconic acid from acetate by engineering acid-tolerant Escherichia coli W. Biotechnol Bioeng. 2018;115(3):729-38.

18. Karlsson E, Mapelli V, Olsson L. Adipic acid tolerance screening for potential adipic acid production hosts. Microb Cell Fact. 2017;16(1):20.

19. Park HJ, Bae JH, Ko HJ, Lee SH, Sung BH, Han Jl, Sohn JH. Low-pH production of d-lactic acid using newly isolated acid tolerant yeast Pichia kudriavzevii NG7. Biotechnol Bioeng. 2018;115(9):2232-42.

20. Sootsuwan K, Thanonkeo P, Keeratirakha N, Thanonkeo S, Jaisil P, Yamada M. Sorbitol required for cell growth and ethanol production by Zymomonas mobilis under heat, ethanol, and osmotic stresses. Biotechnol Biofuels. 2013:6(1):180.

21. Wang X, He Q, Yang Y, Wang J, Haning K, Hu Y, Wu B, He M, Zhang Y, Bao J, et al. Advances and prospects in metabolic engineering of Zymomonas mobilis. Metab Eng. 2018;50:57-73.

22. He MX, Wu B, Qin H, Ruan ZY, Tan FR, Wang JL, Shui ZX, Dai LC, Zhu QL, Pan K, et al. Zymomonas mobilis: a novel platform for future biorefineries. Biotechnol Biofuels. 2014;7(101):101

23. Yang S, Fei Q, Zhang Y, Contreras LM, Utturkar SM, Brown SD, Himmel $\mathrm{ME}$, Zhang M. Zymomonas mobilis as a model system for production of biofuels and biochemicals. Microb Biotechnol. 2016:9(6):699-717.

24. Liu YF, Hsieh CW, Chang YS, Wung BS. Effect of acetic acid on ethanol production by Zymomonas mobilis mutant strains through continuous adaptation. BMC Biotechnol. 2017;17(1):63.

25. Yang S, Land ML, Klingeman DM, Pelletier DA, Lu TY, Martin SL, Guo HB, Smith JC, Brown SD. Paradigm for industrial strain improvement identifies sodium acetate tolerance loci in Zymomonas mobilis and Saccharomyces cerevisiae. Proc Natl Acad Sci USA. 2010;107(23):10395-400.

26. Huang S, Xue T, Wang Z, Ma Y, He X, Hong J, Zou S, Song H, Zhang M. Furfural-tolerant Zymomonas mobilis derived from error-prone PCR-based whole genome shuffling and their tolerant mechanism. Appl Microbiol Biotechnol. 2018;102(7):3337-47.

27. Shui ZX, Qin H, Wu B, Ruan ZY, Wang LS, Tan FR, Wang JL, Tang XY, Dai LC, Hu GQ, et al. Adaptive laboratory evolution of ethanologenic Zymomonas mobilis strain tolerant to furfural and acetic acid inhibitors. Appl Microbiol Biotechnol. 2015:99(13):5739-48.

28. Mohagheghi A, Linger JG, Yang S, Smith H, Dowe N, Zhang M, Pienkos PT. Improving a recombinant Zymomonas mobilis strain $8 \mathrm{~b}$ through continuous adaptation on dilute acid pretreated corn stover hydrolysate. Biotechnol Biofuels. 2015:8:55 
29. Yi X, Gu H, Gao Q, Liu ZL, Bao J. Transcriptome analysis of Zymomonas mobilis ZM4 reveals mechanisms of tolerance and detoxification of phenolic aldehyde inhibitors from lignocellulose pretreatment. Biotechnol Biofuels. 2015;8:153.

30. Baumler DJ, Hung KF, Bose JL, Vykhodets BM, Cheng CM, Jeong KC, Kaspar CW. Enhancement of acid tolerance in Zymomonas mobilis by a proton-buffering peptide. Appl Biochem Biotechnol. 2006;134(1):15-26.

31. Wu B, Qin H, Yang Y, Duan G, Yang S, Xin F, Zhao C, Shao H, Wang Y, Zhu Q, et al. Engineered Zymomonas mobilis tolerant to acetic acid and low pH via multiplex atmospheric and room temperature plasma mutagenesis. Biotechnol Biofuels. 2019;12:10.

32. Gonzalez-Ramos D, Gorter de Vries AR, Grijseels SS, van den Berkum MC, Swinnen S, van Broek M, Nevoigt E, Daran JM, Pronk JT, van Maris AJ. A new laboratory evolution approach to select for constitutive acetic acid tolerance in Saccharomyces cerevisiae and identification of causal mutations. Biotechnol Biofuels. 2016;9:173.

33. Ju SY, Kim JH, Lee PC. Long-term adaptive evolution of Leuconostoc mesenteroides for enhancement of lactic acid tolerance and production. Biotechnol Biofuels. 2016;9:240.

34. Kurosawa K, Laser J, Sinskey AJ. Tolerance and adaptive evolution of triacylglycerol-producing Rhodococcus opacus to lignocellulose-derived inhibitors. Biotechnol Biofuels. 2015;8:76.

35. LaCroix RA, Sandberg TE, O'Brien EJ, Utrilla J, Ebrahim A, Guzman GI, Szubin R, Palsson BO, Feist AM. Use of adaptive laboratory evolution to discover key mutations enabling rapid growth of Escherichia coli K-12 MG1655 on glucose minimal medium. Appl Environ Microbiol. 2015:81(1):17-30

36. McCloskey D, Xu S, Sandberg TE, Brunk E, Hefner Y, Szubin R, Feist AM, Palsson BO. Adaptive laboratory evolution resolves energy depletion to maintain high aromatic metabolite phenotypes in Escherichia coli strains lacking the phosphotransferase system. Metab Eng. 2018;48:233-42.

37. Chen S, Xu Y. Adaptive evolution of Saccharomyces cerevisiae with enhanced ethanol tolerance for Chinese rice wine fermentation. Appl Biochem Biotechnol. 2014;173(7):1940-54.

38. Gonzalez-Ramos D. Gorter de Vries AR, Grijseels SS, van Berkum MC, Swinnen S, van den Broek M, Nevoigt E, Daran JM, Pronk JT, van Maris AJ: a new laboratory evolution approach to select for constitutive acetic acid tolerance in Saccharomyces cerevisiae and identification of causal mutations. Biotechnol Biofuels. 2016;9(1):173.

39. Wu CW, Spike T, Klingeman DM, Rodriguez M, Bremer VR, Brown SD. Generation and Characterization of Acid Tolerant Fibrobacter succinogenes S85. Sci Rep. 2017;7(1):2277.

40. Dunn KL, Rao CV. High-throughput sequencing reveals adaptationinduced mutations in pentose-fermenting strains of Zymomonas mobilis. Biotechnol Bioeng. 2015;112(11):2228-40.

41. Mohagheghi A, Linger J, Smith H, Yang S, Dowe N, Pienkos PT. Improving xylose utilization by recombinant Zymomonas mobilis strain $8 \mathrm{~b}$ through adaptation using 2-deoxyglucose. Biotechnol Biofuels. 2014;7(1):19.

42. Agrawal M, Mao Z, Chen RR. Adaptation yields a highly efficient xylose-fermenting Zymomonas mobilis strain. Biotechnol Bioeng. 2010;108(4):777-85

43. Yang S, Pelletier DA, Lu TY, Brown SD. The Zymomonas mobilis regulator hfa contributes to tolerance against multiple lignocellulosic pretreatment inhibitors. BMC Microbiol. 2010;10(1):135.

44. Liu X, Jia B, Sun X, Ai J, Wang L, Wang C, Zhao F, Zhan J, Huang W. Effect of initial ph on growth characteristics and fermentation properties of Saccharomyces cerevisiae. J Food Sci. 2015;80(4):M800-8.

45. Yang S, Vera JM, Grass J, Savvakis G, Moskvin OV, Yang Y, Mcllwain SJ, Lyu Y, Zinonos I, Hebert AS, et al. Complete genome sequence and the expression pattern of plasmids of the model ethanologen Zymomonas mobilis ZM4 and its xylose-utilizing derivatives 8b and 2032. Biotechnol Biofuels. 2018;11:125.

46. Gu W, Zhao G, Eddy C, Jensen RA. Imidazole acetol phosphate aminotransferase in Zymomonas mobilis: molecular genetic, biochemical, and evolutionary analyses. J Bacteriol. 1995;177(6):1576-84.

47. Hossain MM, Tani C, Suzuki T, Taguchi F, Ezawa T, Ichinose Y. Polyphosphate kinase is essential for swarming motility, tolerance to environmental stresses, and virulence in Pseudomonas syringae pv. tabaci 6605. PhysiolMol Plant. 2008;72(4-6):122-7.
48. Jagannathan V, Kaur P, Datta S. Polyphosphate kinase from M. tuberculosis: an Interconnect between the genetic and biochemical role. PLoS ONE. 2010;5(12):e14336.

49. Price-Carter M, Fazzio TG, Vallbona El, Roth JR. Polyphosphate kinase protects Salmonella enterica from weak organic acid stress. J Bacteriol. 2005;187(9):3088-99.

50. Rudat AK, Pokhrel A, Green TJ, Gray MJ. Mutations in Escherichia coli polyphosphate kinase that lead to dramatically increased in vivo polyphosphate Levels. J Bacteriol. 2018;200(6):e00697.

51. Seufferheld MJ, Alvarez HM, Farias ME. Role of polyphosphates in microbial adaptation to extreme environments. Appl Environ Microbiol. 2008;74(19):5867-74.

52. Muller WEG, Schroder HC, Wang X. Inorganic polyphosphates as storage for and generator of metabolic energy in the extracellular matrix. Chem Rev. 2019;119(24):12337-74.

53. Zhu Y, Huang W, Lee SS, Xu W. Crystal structure of a polyphosphate kinase and its implications for polyphosphate synthesis. EMBO Rep. 2005;6(7):681-7.

54. Ruggerone P, Murakami S, Pos KM, Vargiu AV. RND efflux pumps: structural information translated into function and inhibition mechanisms. Curr Top Med Chem. 2013;13(24):3079-100.

55. Krogh A, Larsson B, von Heijne G, Sonnhammer EL. Predicting transmembrane protein topology with a hidden Markov model: application to complete genomes. J Mol Biol. 2001;305(3):567-80.

56. Blair JM, Piddock LJ. Structure, function and inhibition of RND efflux pumps in Gram-negative bacteria: an update. Curr Opin Microbiol. 2009:12(5):512-9.

57. Solovyev V, Salamov A. Automatic annotation of microbial genomes and metagenomic sequences. In: Li RW, editor. Metagenomics and its applications in agriculture. Hauppauge: Nova Science Publishers; 2011. p. 61-78.

58. Chiang SM, Schellhorn HE. Regulators of oxidative stress response genes in Escherichia coli and their functional conservation in bacteria. Arch Biochem Biophys. 2012;525(2):161-9.

59. Maurer LM, Yohannes E, Bondurant SS, Radmacher M, Slonczewski JL. $\mathrm{pH}$ regulates genes for flagellar motility, catabolism, and oxidative stress in Escherichia coli K-12. J Bacteriol. 2005;187(1):304-19.

60. Quivey RG, Faustoferri RC, Santiago B, Baker J, Cross B, Xiao J. Acidadaptive responses of Streptococcus mutans, and mechanisms of integration with oxidative stress. In: Bruijn FJ, editor. Stress and environmental regulation of gene expression and adaptation in bacteria. Hoboken: Wiley; 2016.

61. Geng P, Zhang L, Shi GY. Omics analysis of acetic acid tolerance in Saccharomyces cerevisiae. World J Microbiol Biotechnol. 2017;33(5):94.

62. Chang YY, Cronan JE Jr. Membrane cyclopropane fatty acid content is a major factor in acid resistance of Escherichia coli. Mol Microbiol. 1999;33(2):249-59.

63. Budin-Verneuil A, Maguin E, Auffray Y, Ehrlich SD, Pichereau V. Transcriptional analysis of the cyclopropane fatty acid synthase gene of Lactococcus lactis MG1363 at low pH. FEMS Microbiol Lett. 2005;250(2):189-94.

64. Matsui R, Cvitkovitch D. Acid tolerance mechanisms utilized by Streptococcus mutans. Future Microbiol. 2010;5(3):403-17.

65. Len ACL, Harty DWS, Jacques NA. Proteome analysis of Streptococcus mutans metabolic phenotype during acid tolerance. Microbiology. 2004;150(Pt 5):1353-66.

66. Sheng J, Marquis RE. Enhanced acid resistance of oral streptococci at lethal $\mathrm{pH}$ values associated with acid-tolerant catabolism and with ATP synthase activity. FEMS Microbiol Lett. 2006;262(1):93-8.

67. Jacobson TB, Adamczyk PA, Stevenson DM, Regner M, Ralph J, Reed JL, Amador-Noguez D. ${ }^{2} \mathrm{H}$ and ${ }^{13} \mathrm{C}$ metabolic flux analysis elucidates in vivo thermodynamics of the ED pathway in Zymomonas mobilis. Metab Eng. 2019;54:301-16.

68. Kremer TA, LaSarre B, Posto AL, McKinlay JB. $N_{2}$ gas is an effective fertilizer for bioethanol production by Zymomonas mobilis. Proc Natl Acad Sci USA. 2015;112(7):2222-6.

69. Gregor MF, Hotamisligil GS. Thematic review series: adipocyte biology adipocyte stress: the endoplasmic reticulum and metabolic disease. J Lipid Res. 2007;48(9):1905-14.

70. Wilkens S. Structure and mechanism of $A B C$ transporters. F1000Prime Rep. 2015;7:14. 
71. Sun J, Deng Z, Yan A. Bacterial multidrug efflux pumps: mechanisms, physiology and pharmacological exploitations. Biochem Biophys Res Commun. 2014;453(2):254-67.

72. Nikaido H, Takatsuka Y. Mechanisms of RND multidrug efflux pumps. Biochim Biophys Acta. 2009;1794(5):769-81.

73. Guan N, Liu L. Microbial response to acid stress: mechanisms and applications. Appl Microbiol Biotechnol. 2019;104(1):51-65.

74. Capaldi RA, Aggeler R. Mechanism of the F(1)F(0)-type ATP synthase, a biological rotary motor. Trends Biochem Sci. 2002;27(3):154-60.

75. Liu Y, Tang H, Lin Z, Xu P. Mechanisms of acid tolerance in bacteria and prospects in biotechnology and bioremediation. Biotechnol Adv. 2015;33(7):1484-92

76. Kuhnert WL, Zheng G, Faustoferri RC, Quivey RG Jr. The F-ATPase operon promoter of Streptococcus mutans is transcriptionally regulated in response to external pH. J Bacteriol. 2004;186(24):8524-8.

77. Panicucci B, Gahura O, Zikova A. Trypanosoma brucei TbIF1 inhibits the essential $F_{1}$-ATPase in the infectious form of the parasite. PLoS Negl Trop Dis. 2017:11(4):e0005552.

78. Rutkis R, Galinina N, Strazdina I, Kalnenieks U. The inefficient aerobic energetics of Zymomonas mobilis: identifying the bottleneck. J Basic Microbiol. 2014;54(10):1090-7.

79. Kalnenieks U, Galinina N, Irbe I. Toma M: energy coupling sites in the electron transport chain of Zymomonas mobilis. FEMS Microbiol Lett. 1995:133:99-104.

80. Chen H, Richardson AE, Gartner E, Djordjevic MA, Roughley RJ, Rolfe BG. Construction of an acid-tolerant Rhizobium leguminosarum biovar trifoli strain with enhanced capacity for nitrogen fixation. Appl Environ Microbiol. 1991;57(7):2005-11.

81. Krulwich TA, Sachs G, Padan E. Molecular aspects of bacterial pH sensing and homeostasis. Nat Rev Microbiol. 2011;9(5):330-43.

82. Yang S, Franden MA, Brown SD, Chou YC, Pienkos PT, Zhang M. Insights into acetate toxicity in Zymomonas mobilis $8 \mathrm{~b}$ using different substrates. Biotechnol Biofuels. 2014;7(1):140.

83. He M, Wu B, Shui Z, Hu Q, Wang W, Tan F, Tang X, Zhu Q, Pan K, Li Q, et al. Transcriptome profiling of Zymomonas mobilis under ethanol stress. Biotechnol Biofuels. 2012;5(1):75.
84. Lemos JA, Burne RA. Regulation and physiological significance of ClpC and ClpP in Streptococcus mutans. J Bacteriol. 2002;184(22):6357-66.

85. Biswas S, Biswas I. Role of HtrA in surface protein expression and biofilm formation by Streptococcus mutans. Infect Immun. 2005;73(10):6923-34

86. Yang Y, Shen W, Huang J, Li R, Xiao Y, Wei H, Chou YC, Zhang M, Himmel $M E, C$ Chen $S$, et al. Prediction and characterization of promoters and ribosomal binding sites of Zymomonas mobilis in system biology era. Biotechnol Biofuels. 2019;12:52.

87. Krulwich TA. Alkaliphiles: 'basic' molecular problems of $\mathrm{pH}$ tolerance and bioenergetics. Mol Microbiol. 1995;15(3):403-10.

88. Kalnenieks U, Balodite E, Rutkis R. Metabolic engineering of bacterial respiration: high vs. low P/O and the case of Zymomonas mobilis. Front Bioeng Biotechnol. 2019;7:327.

89. Gao X, Jiang $L$, Zhu L, Xu Q, Xu X, Huang H. Tailoring of global transcription sigma $\mathrm{D}$ factor by random mutagenesis to improve Escherichia coli tolerance towards low-pHs. J Biotechnol. 2016;224:55-63.

90. Yang S, Pan C, Hurst GB, Dice L, Davison BH, Brown SD. Elucidation of Zymomonas mobilis physiology and stress responses by quantitative proteomics and transcriptomics. Front Microbiol. 2014;5:246.

91. He Q, Yang Y, Yang S, Donohoe BS, Van Wychen S, Zhang M, Himmel ME, Knoshaug EP. Oleaginicity of the yeast strain Saccharomyces cerevisiae D5A. Biotechnol Biofuels. 2018;11:258.

92. Gibson DG, Young L, Chuang RY, Venter JC, Hutchison CA 3rd, Smith HO Enzymatic assembly of DNA molecules up to several hundred kilobases. Nat Methods. 2009;6(5):343-5.

93. Yang S, Mohagheghi A, Franden MA, Chou YC, Chen X, Dowe N, Himmel ME, Zhang M. Metabolic engineering of Zymomonas mobilis for 2,3-butanediol production from lignocellulosic biomass sugars. Biotechnol Biofuels. 2016;9(1):189.

\section{Publisher's Note}

Springer Nature remains neutral with regard to jurisdictional claims in published maps and institutional affiliations.
Ready to submit your research? Choose BMC and benefit from:

- fast, convenient online submission

- thorough peer review by experienced researchers in your field

- rapid publication on acceptance

- support for research data, including large and complex data types

- gold Open Access which fosters wider collaboration and increased citations

- maximum visibility for your research: over $100 \mathrm{M}$ website views per year

At $\mathrm{BMC}$, research is always in progress.

Learn more biomedcentral.com/submissions 